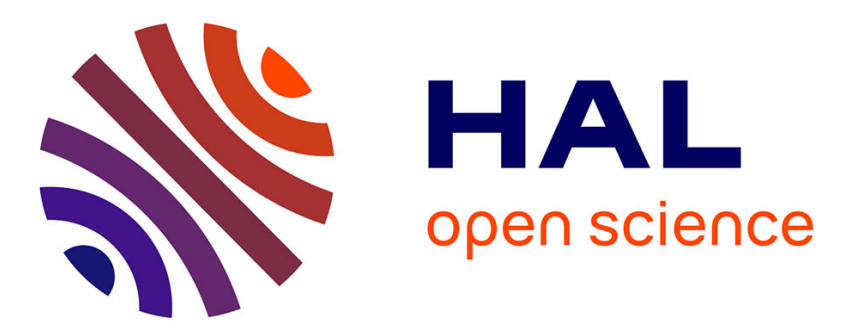

\title{
Synthesis and properties of self-crosslinkable thermoplastic polyurethanes
}

\author{
Aude Lapprand, Françoise Méchin, Jean-Pierre Pascault
}

\section{To cite this version:}

Aude Lapprand, Françoise Méchin, Jean-Pierre Pascault. Synthesis and properties of self-crosslinkable thermoplastic polyurethanes. Journal of Applied Polymer Science, 2007, 105 (1), pp.99-113. hal00373053

\section{HAL Id: hal-00373053 \\ https://hal.science/hal-00373053}

Submitted on 8 Dec 2021

HAL is a multi-disciplinary open access archive for the deposit and dissemination of scientific research documents, whether they are published or not. The documents may come from teaching and research institutions in France or abroad, or from public or private research centers.
L'archive ouverte pluridisciplinaire HAL, est destinée au dépôt et à la diffusion de documents scientifiques de niveau recherche, publiés ou non, émanant des établissements d'enseignement et de recherche français ou étrangers, des laboratoires publics ou privés. 


\title{
Synthesis and Properties of Self-Crosslinkable Thermoplastic Polyurethanes
}

\author{
A. Lapprand, F. Méchin, J.-P. Pascault \\ Ingénierie des Matériaux Polymères, Unité Mixte de Recherche ${ }^{\circ} 5223$, Centre National de la Recherche \\ Scientifique (UMR CNRS) 5627, Laboratoire des Matériaux Macromoléculaires, Institut National des \\ Sciences Appliquées de Lyon, Bât. Jules Verne, 20 Avenue A. Einstein, 69621 Villeurbanne Cedex, France
}

\begin{abstract}
The chemical modification of a thermoplastic polyurethane (TPU) has been realized by the grafting of polyisocyanates onto urethane groups through allophanate bonds to prepare selfcrosslinkable but still thermoplastic materials. Because of the lateral isocyanate groups, the resulting polymer can be easily crosslinked by the ambient moisture. However, because of the highly viscous character of the TPU even at a high temperature, this chemical reaction must be performed with a twin-screw extruder above $190^{\circ} \mathrm{C}$. The ability of linear, segmented TPUs to undergo physical (micro)structuration that strongly depends on their thermal history has been widely described in the literature, and these transformations usually occur in the same temperature range as that used for performing our chemical reactions. Moreover, the thermally reversible character of urethane and allophanate bonds above $\sim 170^{\circ} \mathrm{C}$ is also well-known. Therefore, the precise characterization of the thermomechanical properties of the initial and modified materials is quite delicate because microstructural phenomena and chemical rearrangements can compete and always have to be considered simultaneously. Considering these restrictions, we have nevertheless demonstrated that the structural transformation is faster than crosslinking for a partially crosslinked TPU, but microphase separation is no longer possible for a TPU with a gel fraction higher than $50 \%$. The chemical crosslinks of the modified TPU are reversible, but they still allow an important increase in the thermomechanical properties at a high temperature.
\end{abstract}

Keywords: thermoplastic polyurethanes; chemical modification; reactive extrusion; crosslinking This article is dedicated to the memory of Professor Marian Kryszewski.

Published in Journal of Applied Polymer Science, Vol. 105, pp. 99-113 (2007) 


\section{INTRODUCTION}

Linear, segmented polyurethanes (PUs) that consist of alternating soft segments (SSs) and hard segments (HSs) offer unique possibilities for tailor-made polymers through the variation of the block length and composition. The SSs are typically polyether or polyester and provide the flexible character of the polymers. These segments are connected by HSs formed from the reaction of diisocyanates with diol chain extenders. Thermodynamic immiscibility between HSs and SSs induces phase separation and generates a two-phase morphology in these segmented block copolymers [1].

Because of their numerous industrial applications [2], these materials have received considerable attention. Many characterization techniques have been used to try to understand the relationship between the chemical architectures, morphologies, and mechanical properties of thermoplastic polyurethanes (TPUs). It is widely accepted that the engineering properties of these (A-B) ${ }_{n}$-type thermoplastic elastomers are determined to a large extent by phase separation. Thermal studies of TPUs are complicated by several factors: first, one of the blocks (the HS) is capable of crystallization, and the morphology is very sensitive to the thermal history, and second, there is a most probable distribution in the HS length. This results in a broadening of the transitions, and fractionation by the $\mathrm{HS}$ length can occur during crystallization. By combining many different techniques such as differential scanning calorimetry (DSC), small-angle X-ray scattering (SAXS), Fourier transform infrared (FTIR), and wide-angle X-ray diffusion (WAXD), Koberstein and coworkers [3-8] were able to fully characterize a series of TPUs. The materials were based on 4,4'-methylene bis(phenyl isocyanate) (MDI) and 1,4butanediol (BDO) for their HSs, whereas the SSs were formed by a macrodiol (polyoxypropylene endcapped with $30 \mathrm{wt} \%$ polyoxyethylene). The materials were synthesized in bulk and then annealed above the HS melting point. The thermal properties of these materials depended strongly on the processing temperature [8]. Simultaneous FTIR/DSC [4] and synchrotron SAXS/DSC [3,5,8] experiments were successful in elucidating the origins of the processing-temperature-dependent nature of TPUs. In particular, real-time synchrotron SAXS and WAXD [8] measurements of the kinetics of microphase separation and crystallization showed that the competition between these two processes determined the final morphologies. DSC annealing experiments have been used to probe the temperature dependence of microphase separation. For TPUs with MDI/BDO-based HSs, three endotherms are usually detected. A first so-called annealing endotherm $\left(T_{I}\right)$ is observed at $20-30^{\circ} \mathrm{C}$ higher than the applied annealing temperature $\left(T_{a}\right)$. Some authors [9] have suggested that this endotherm is related to some relaxation effects of the polymer chains in the HS-rich phase.

The other two endotherms are detected at higher temperatures up to $250^{\circ} \mathrm{C}$. The intermediate temperature endotherm $\left(T_{I I}\right)$ has been associated with the disruption of the microdomain structure that occurs at the microphase mixing transition (MMT); this is also called the microphase separation transition (MST) temperature. This interpretation was confirmed by simultaneous SAXS/DSC experiments [5]. The interpretation of the third endotherm $\left(T_{I I I}\right)$ is simpler; it results from the melting of microcrystalline HS. According to Koberstein's experiments [4], for all annealing conditions, the $T_{I \prime}$ endotherm occurs before this $T_{I / I}$ endotherm, implying that the disruption of the disordered crystalline and/or nanocrystalline hard microdomains precedes the melting of the microcrystalline HS. For a given TPU, the $T_{\| /}$and $T_{I / l}$ endotherms depend on $T_{a}$. For a $T_{a}$ above the MST, HS crystallization occurs from a homogeneous solution of HS and SS; the level of crystallinity under these conditions is controlled only by undercooling. When $T_{a}$ is below the MST, there are two regimes of behavior depending on whether $T_{a}$ is above or approaching the hard-microdomain glass-transition temperature $\left(T_{g}\right)$; both are controlled by diffusion. Concordant results were found by other authors $[10,11]$ because they 
determined the maximum rate of microphase separation toward $80-107^{\circ} \mathrm{C}$ for another polyetherbased TPU. Moreover, the Avrami equation could be used to describe the phase-separation behavior. Lee and coworkers $[12,13]$ found that the MST could be interpreted to proceed first by a nucleation and growth mechanism [Avrami exponent $(n)=2$ ] and then by a diffusion-dominated mechanism $(n=$ 0.5). Countless TPU formulations exist, varying in their monomer type and chemical composition, and the microphase-separated morphology depends on the fabrication and processing rate as well as the molecular formulation. The $T_{\| /}$and $T_{\text {III }}$ endotherms depend strongly on the HS (diisocyanate plus diol) structure, HS length, SS/HS interactions, and degree of immiscibility. For all these reasons, the reported values of $T_{\| /}$and $T_{I I I}$ and the dynamics of the phase separation and crystallization of the HS strongly depend on the TPU studied. When coupled with DSC measurements, the rheological technique has been shown to be a complementary tool for monitoring these complex phase transitions of TPUs from and to the melt. By performing viscoelastic measurements during well-defined thermal histories, Grizzuti and coworkers $[14,15]$ were able to show that the microphase transition is characterized by going through a critical gel state. Rheological measurements revealed that the microphase separation between HSs and SSs and the concurrent HS crystallization produce a sol-gel type of transition. When there is heating up to the melt, the reverse process occurs, but with different critical gel properties.

We have pointed out that thermal studies of TPUs are complicated by several factors, and two factors have been listed first. A third one, a very difficult issue, is the control of the melt state because of the possibility of the dissociation of urethane bonds and isocyanate side reactions at high temperatures. It is generally admitted that the urethane bond is unstable above $170^{\circ} \mathrm{C}$ in the solid and molten liquid states. The major degradation mechanism is dissociation to free isocyanate and alcohol. After heating at a high temperature, one may expect a most probable molar mass distribution after the random scission process during heating followed by the random reformation of urethanes during cooling, as shown by many authors [16,17]. During studies of the microstructures of TPUs, degradation has generally been observed but neglected $[18,19]$. Usually, this kind of side reaction induces a change in the molar mass and/or molar mass distribution of the samples $[20,21]$. For example, at high $T_{a}{ }^{\prime}$ s, some molar mass increases, even for insoluble gels, can be noticed, and they are attributed to the effect of the formation of allophanate bonds by side reactions [19]. As mentioned by Hu and Koberstein [22], these branching reactions occurring in a disordered TPU can hinder HS crystallization during cooling and annealing at low temperatures.

In fact, most of the studies dealing with the role of branches and crosslinks relate to PUs initially crosslinked during their synthesis, either by the introduction of precursors with a functionality higher than 2 [23-25] or by the use of excess isocyanate [26-28]. According to these studies, the impacts of the crosslinking on the MST and on the crystallization rates are not clear. Moreover, with these ways of modification, no improvement in the thermomechanical properties has ever been measured. Recently, another method has been developed [29-32]. During the first step, polyisocyanates were grafted to an already synthesized TPU through allophanate functions. Then, the grafted TPU was able to react and crosslink during a second step at low (room) temperatures with the help of humidity or radiation.

The reactions during the first step between isocyanates and urethanes were studied on a model diurethane [33] at a high temperature $\left(\geq 170^{\circ} \mathrm{C}\right)$, with several $\mathrm{NCO} /$ urethane ratios, without a catalyst, and with aromatic MDI or the cycloaliphatic trimer of isophorone diisocyanate (tIPDI). When the mixture was cooled to room temperature, allophanates could be clearly identified as the main product of the reactions. These results proved the possibility of creating some crosslinks through allophanate 
functions just by the mixing of polyisocyanate with a TPU at a high temperature. In this article, the chemistry developed during the study on the model diurethane is applied to a polymer with reactive extrusion. Our aim is to prepare self-crosslinkable TPUs via a continuous process and, if possible, to be able to reprocess the reactive granules several times. In the first part of the article, we describe the two steps leading to a crosslinked TPU. In the second part, a method based on the use of DSC and rheological techniques is developed to identify the phase transitions of the initial and modified TPUs after different thermal histories, including isothermal annealing after cooling from the melt and heating cycles following isothermal annealing. Our aim is not to revisit the different transition stages occurring after different thermal treatments but just to be able to use these two techniques in a proper way, so that phenomena associated with microstructuration, on the one hand, and real improvements in the thermomechanical properties due to crosslinking, on the other hand, can be distinguished and their relative importance can be evaluated.

\section{EXPERIMENTAL}

\section{Materials}

The TPU used in this study is a commercial material, Estane 58 888, provided by Noveon Europe (Brussels, Belgium). According to the ${ }^{1} \mathrm{H}-\mathrm{NMR}$ and ${ }^{13} \mathrm{C}-\mathrm{NMR}$ analysis (not presented here), this $\mathrm{PU}$ is based on $\mathrm{MDI}, \mathrm{BDO}$, and poly(tetramethylene oxide) (number-average molecular weight $\approx 1000 \mathrm{~g} / \mathrm{mol}$ ) as the SSs. The HS content is about $46 \mathrm{wt} \%$. Before each use, the TPU was dried at $80^{\circ} \mathrm{C}$ in an oven. The pellets were pressed $2 \mathrm{~min}$ at $200^{\circ} \mathrm{C}$ to obtain 2-mm-thick samples, which were used for each analysis. MDI and tIPDI were used as reactive modifiers for the TPU. MDI, provided by Hunstman Advanced Materials (Everley, Belgium) (Suprasec 1100), contains about 98\% MDI and about 2\% $2,4^{\prime}$-diphenylmethane diisocyanate and shows a melting temperature of $38^{\circ} \mathrm{C}$. It was kept at $4^{\circ} \mathrm{C}$ to prevent dimer formation. The trimer of IPDI, supplied by Degussa Gmbh (Düsseldorf, Germany) (Vestanat T 1890/100), is an amorphous polyisocyanate with $T_{g}=70^{\circ} \mathrm{C}$. The so-called trimer of IPDI is formed by many oligomers, not only trimers but also pentamers, heptamers, or higher molar mass oligomers of IPDI resulting from the addition of isophorone diisocyanate [33,34].

\section{Reactive extrusion}

For chemical modification, a Werner \& Pfleiderer (Tamm, Germany) ZSK 25 corotating twin-screw extruder (length $/$ diameter ratio $=36$, diameter $=34 \mathrm{~mm}$ ) was used. The machine was operated with a screw speed of $350 \mathrm{rpm}$. The heating zone temperature decreased from 200 to $190^{\circ} \mathrm{C}$ when MDI was used and from 210 to $190^{\circ} \mathrm{C}$ for modification with tIPDI. A Brabender (Hackensack, NJ) single-screw extruder (length/diameter $=25$, diameter $=19 \mathrm{~mm}$ ) was then used to reprocess the granules so that we could study the materials under industrial conditions. The screw speed and the heating temperature were selected according to the compounds (between 20 and $60 \mathrm{rpm}$ and between 170 and $220^{\circ} \mathrm{C}$, respectively).

\section{Analytical techniques}

Size exclusion chromatography measurements were performed in tetrahydrofuran (THF) with a Waters chromatograph (Milford, MA) equipped with three Microstyragel columns and a refractive-index detector. The column calibration was done with reference to polystyrene standards. A mixture of THF and di-n-butylamine ( $0.5 \mathrm{wt} \%)$ was used as a solvent. The secondary amines were expected to react with and to neutralize the unreacted isocyanates. The sample concentration was about $3 \mathrm{~g} / \mathrm{L}$. For 
partially soluble samples, the gel content was evaluated after the soluble fraction, which could be determined from the ratio of the area of the observed polymer peak to that of a fully soluble sample with exactly the same initial concentration; this simple method was shown to lead to the same results as a more time-consuming mass measurement [32].

High-resolution liquid NMR spectroscopy was carried out with a Bruker (Marne La Vallée, France) DRX 400 spectrometer operating at $400 \mathrm{MHz}$ for ${ }^{1} \mathrm{H}$ and at $100.6 \mathrm{MHz}$ for ${ }^{13} \mathrm{C}$. Spectra were obtained with a QNP 5-mm probe at $298 \mathrm{~K}$. Deuterated chloroform $\left(\mathrm{CDCl}_{3}\right)$ and dimethyl sulfoxide were used as solvents. The chemical shifts (ppm) are given with reference to internal tetramethylsilane [33].

A Pyris 1 differential scanning calorimeter (Perkin-Elmer, Waltham, MA) with an indium standard was used for calorimetric measurements. The analysis was performed under a nitrogen gas atmosphere with aluminum pans, which usually contained $10-30 \mathrm{mg}$ of the sample. Each analysis was preceded by a measurement under the same conditions on an empty pan. The blank heat flow was then subtracted from the heat flow of the studied sample.

A mechanical spectrometer (Rheometrics Scientific, Marne La Vallée, France) was used in the oscillatory mode with parallel plate fixtures ( $25 \mathrm{~mm}$ in diameter) or torsion jaws. The dynamic storage modulus $\left(G^{\prime}\right)$ and dynamic loss modulus $\left(G^{\prime \prime}\right)$ were measured at different angular frequencies $(\omega)$ ranging from 1 to $100 \mathrm{rad} / \mathrm{s}$ as a function of the annealing time $\left(t_{a}\right)$ at different temperatures or as a function of the temperature. A fixed strain of 0.45 was used to ensure that the measurements were taken well within the linear viscoelastic range of the material investigated. A dynamic autotension feature of $1 \mathrm{mg}$ was used to compensate for sample shrinkage in the cooling-heating and phasetransition process.

\section{RESULTS AND DISCUSSION}

\section{Characterization of the initial TPU}

In a first step, the as-received TPU was analyzed by DSC (Fig. 1). The sample did not receive any heat treatment, except for the stage of setting under the press $\left(200^{\circ} \mathrm{C}\right)$ and drying $\left(80^{\circ} \mathrm{C}\right)$. A glass transition was identified at approximately $-50^{\circ} \mathrm{C}$, along with two expected endotherms at 110 and $160^{\circ} \mathrm{C}$ with an end at $\sim 190^{\circ} \mathrm{C}$. The second endotherm [associated with the melting temperature of the hard domains $\left(T_{m}\right)$ ] did not appear as a characteristic narrow endothermic peak as for semi-crystalline polymers but more as a weak, broad peak. This broadening and rather low temperature could be explained by an HS content lower than $50 \mathrm{wt} \%$.

TABLE I. Nomenclature Used for the Thermal Treatments

\begin{tabular}{|l|l|l|}
\hline Designation & Name & Range of values \\
\hline$T^{*}$ & Homogenization temperature & $190-230^{\circ} \mathrm{C}$ \\
$t^{*}$ & Homogenization time & $3 \mathrm{~min}$ \\
$T_{a}$ & Annealing temperature & $50-130^{\circ} \mathrm{C}$ \\
$t_{a}$ & Annealing time & $0-100 \mathrm{~min}$ \\
$+q$ & Heating rate & $5-20^{\circ} \mathrm{C} / \mathrm{min}$ \\
$-q$ & Cooling rate & $10-100^{\circ} \mathrm{C} / \mathrm{min}$ \\
\hline
\end{tabular}




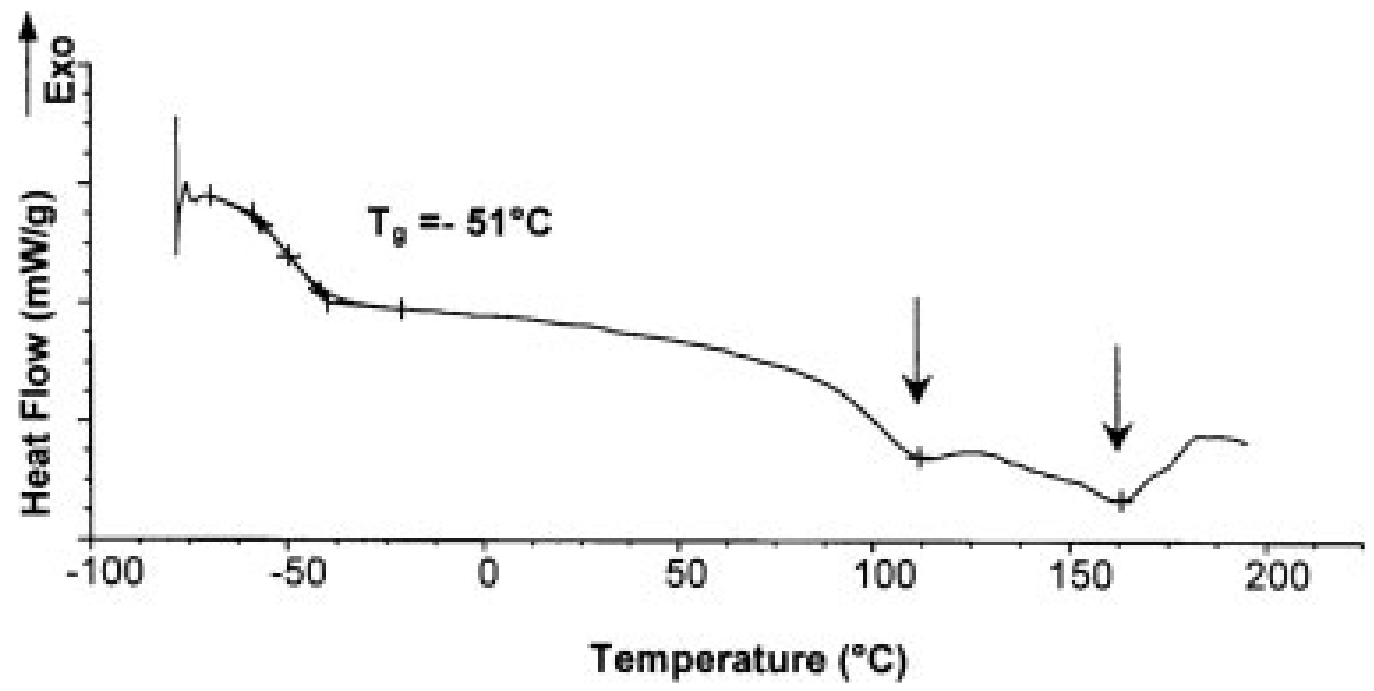

Figure 1. DSC thermogram of the as-received TPU $\left(+q=10^{\circ} \mathrm{C} / \mathrm{min}\right)$.

After this first characterization, different thermal treatments were applied to the polymer. Table I sums up the nomenclature used to designate these thermal treatments performed directly in the DSC apparatus or in the rheometer. For the isothermal study from the melt, the TPU was first heated quickly up to a homogenization temperature $\left(T^{*}\right)$ during a holding time $\left(t^{*}\right)$, then cooled directly at the rate of $-q$ to $T_{a}$, and kept at this temperature for $t_{a}$. Finally, the material underwent a second heating ramp at the rate of $+q$. These thermal treatments were applied to the initial TPU and also to the modified TPU. For this reason, we first have to describe the modifications made on the initial TPU.

\section{Synthesis of the modified TPU}

The TPU and the polyisocyanate (MDI or tIPDI) were mixed by dry blending in the desired proportions (the polyisocyanate content was between 3 and $8 \mathrm{wt} \%$ ) and fed into the first entry of the twin-screw extruder with a mass flow rate of $15 \mathrm{~kg} / \mathrm{h}$. The residence time under these conditions was found equal to $20 \mathrm{~s}$. The modified material was chilled by water, granulated, and dried. Before use, the pellets were pressed $\left(2 \mathrm{~min}\right.$ at $200^{\circ} \mathrm{C}$ ) or re-extruded in a single-screw extruder to obtain ribbons. The isocyanate/urethane ratio was varied between 0.107 and 0.214 for MDI-modified TPU and between 0.055 and 0.110 for tIPDI-modified TPU because higher ratios resulted in a crosslinked material inside the screw. Because of the high reactivity of the pendent NCO groups, special attention must be paid to the pellet conservation between the different steps of the process.

Figure 2 represents the gel content evolution at room temperature and under ambient humidity conditions of the modified TPUs after chemical modification in the twin-screw extruder and reprocessing with the single-screw extruder. From an initially entirely soluble material, a gel fraction appeared in the modified TPU after 1-2 days. With time, the gel content increased up to a plateau. The final value of this plateau after several days increased as the quantity of the added isocyanate during the first extrusion process became higher, with either MDI or tIPDI. However, a quite clear difference in the behavior could be observed; that is, the crosslinking rate was faster if MDI was used for the modification. With the method developed during the study of the model system [33], an MDI (isocyanate/urethane $=0.214$ ) - modified TPU was analyzed by ${ }^{1} \mathrm{H}-\mathrm{NMR}$ and ${ }^{13} \mathrm{C}-\mathrm{NMR}$ under the same conditions. Immediately after the reactive extrusion, the sample was neutralized by diethylamine and then (after THF evaporation) dissolved in $\mathrm{CDCl}_{3}$, so it was entirely soluble. Even though the 
isocyanate/urethane ratio was quite low, we could detect two small peaks at 10.7 and $10.6 \mathrm{ppm}$ in the ${ }^{1} \mathrm{H}-\mathrm{NMR}$ spectra, which were assigned to allophanate functions according to the literature and to our study of the model system [33]. ${ }^{13} \mathrm{C}$-NMR could not provide any further information because of the weakness of the peaks. From a quantitative analysis of the signals found in the ${ }^{1} \mathrm{H}-\mathrm{NMR}$ spectra, it was possible to estimate that on average three to four urethane bonds had reacted to form allophanates on each chain that contained approximately 260 urethane linkages.

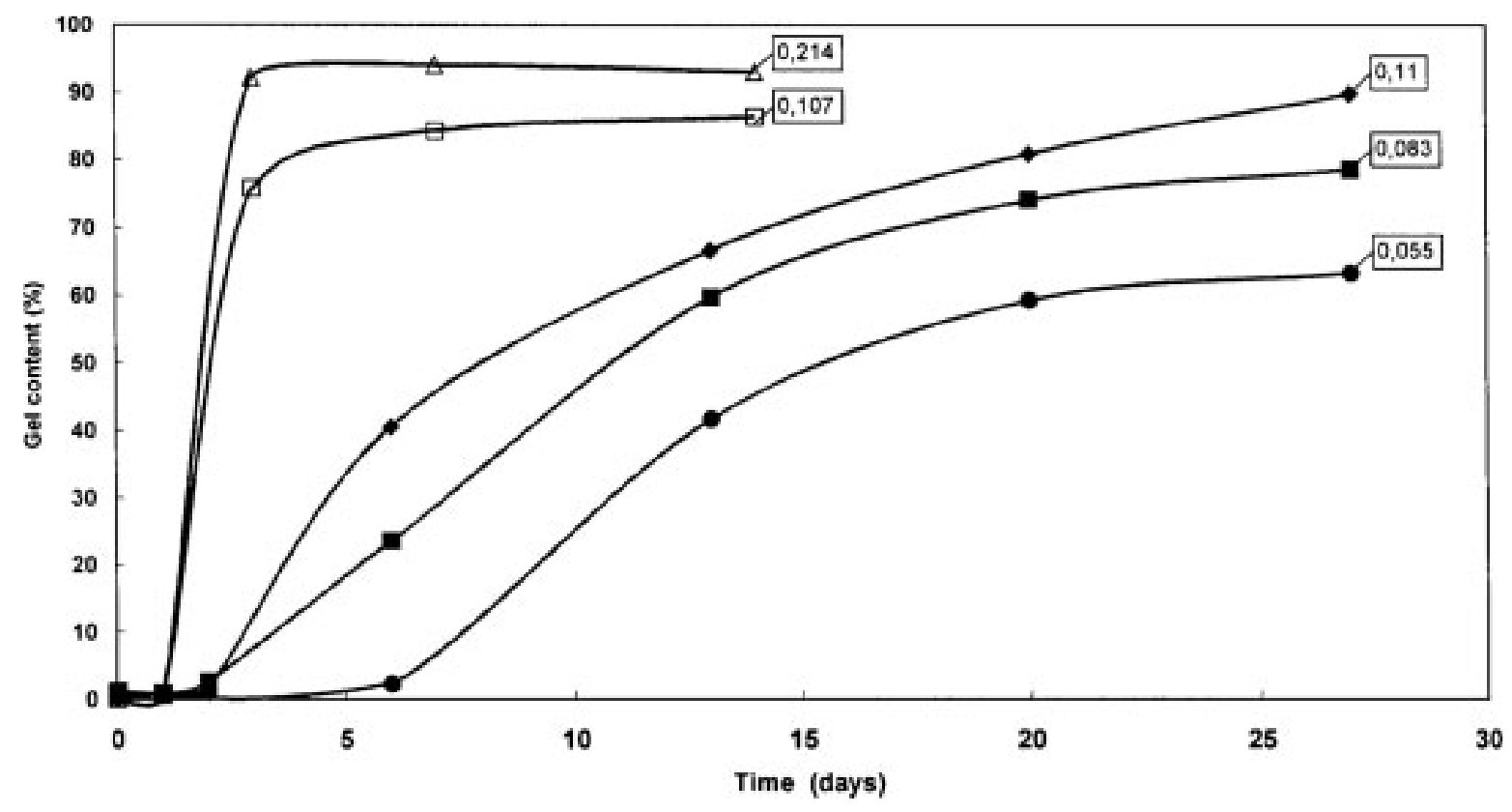

Figure 2. Evolution of the gel content at room temperature for TPUs modified by MDI and by tIDPI in a twin-screw extruder and reprocessed with a single-screw extruder. The filled symbols correspond to the tIPDI-modified TPU, and the open symbols correspond to the MDI-modified TPU. The isocyanateto-urethane ratio is indicated for each species.

Other samples of MDI-modified TPUs were neutralized and dissolved only after being kept a few hours at room temperature under ambient conditions, without any precautions. Their ${ }^{1} \mathrm{H}$ spectra indicated the presence of symmetric aryl-aryl urea groups that could result only from the reaction between a hydrolyzed isocyanate (leading to an amine function) and another, non-hydrolyzed isocyanate. Moreover, the quantities of this urea increased with $t_{a}$ at room temperature. Taking into account the fact that allophanates are the major reaction products identified first in the model diurethane molecule [33] and now in the modified TPU and that the increase in ureas is the only change that occurs in the samples stored at room temperature under air, we can confirm the crosslinking mechanism described in Figure 3:

- When polyisocyanates are added to a PU at a high temperature, for example, in the twin-screw extruder, and further cooled to room temperature, allophanate functions are formed by reactions between urethanes and the excess isocyanate.

- Some of the added polyisocyanates are therefore grafted onto the TPU chains and are still carrying unreacted isocyanate groups. 
- These NCO groups are very reactive toward water molecules and can then hydrolyze when the samples are kept at room temperature under air and ambient humidity, leading to the formation of amines.

- Reactions between isocyanate and amine functions are very fast. Two grafted molecules can then react and form a bridge between chains, resulting in crosslinking.

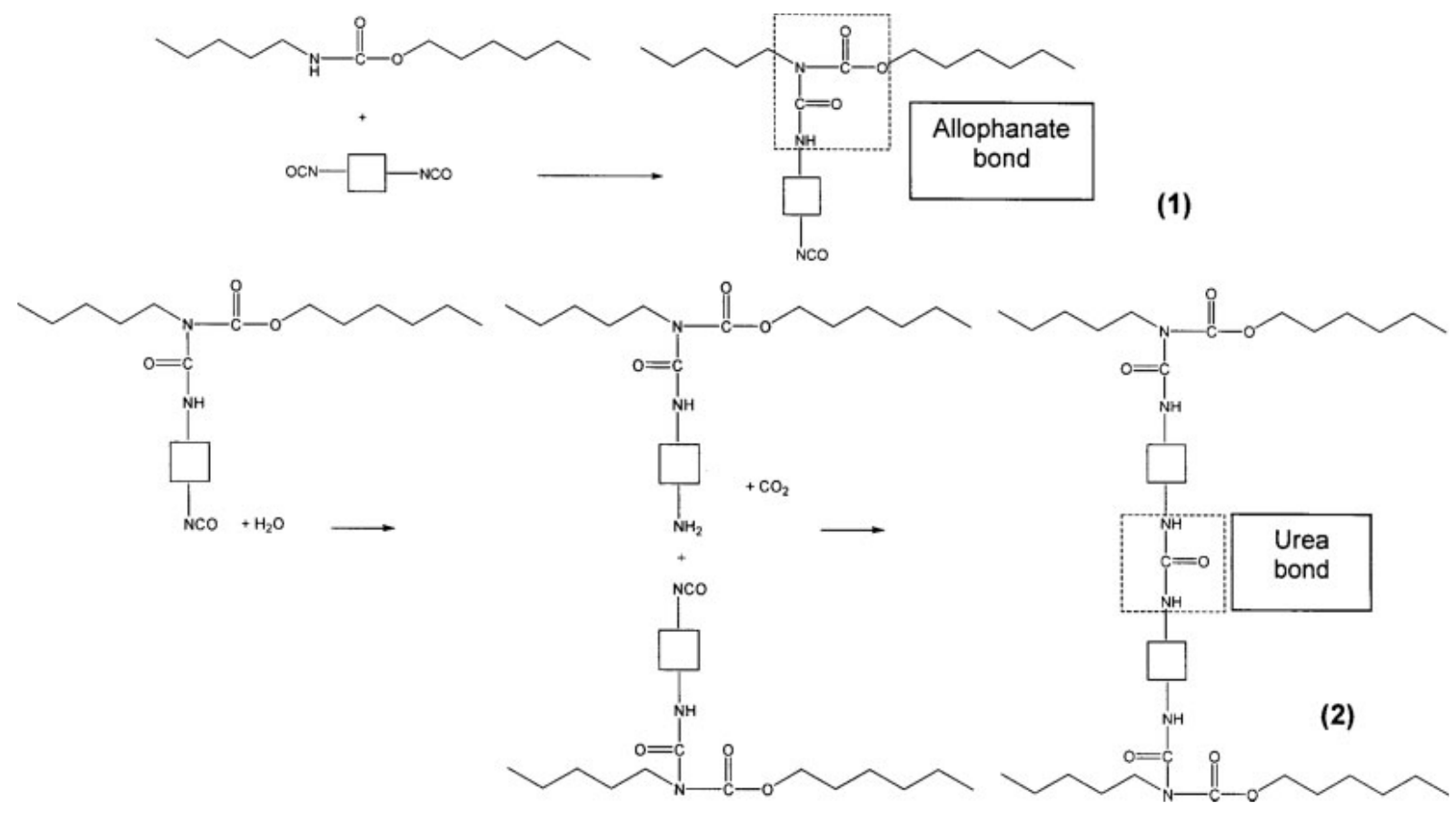

Figure 3. (1) Allophanate formation through the reaction of a urethane function with an isocyanate function and (2) hydrolysis of an isocyanate function followed by the formation of a urea function.

In conclusion, the allophanate bonds, formed by the chemical modification, are responsible for the further TPU crosslinking under ambient conditions. This process assumes enough mobility for the grafted and ungrafted polymer chains at room temperature. As the gel fraction appears after 1 or 2 days, we have now to answer this question: did the reactions leading to chemical crosslinks occur in an amorphous or microstructured/semi-crystalline TPU? To try to answer this question, we have to know the state of the microphase separation between HSs and SSs and the state of the crystallization of hard domains.

\section{Behavior of partially crosslinked TPU}

\section{Microphase structure}

If no more information is pointed out, the modified TPU refers to a MDI-modified TPU (isocyanate/urethane $=0.107$ ) crosslinked at room temperature for enough time to have a $100 \%$ gel content.

The same DSC analysis used for the initial TPU (Fig. 1) was applied to the crosslinked TPU. A $T_{g}$ was determined at $-44^{\circ} \mathrm{C}$ with less important endotherms. This value is still well below the $T_{g}$ that can be calculated for a homogeneous mixing of SS and $\mathrm{HS}\left(\mathrm{ca} .-17^{\circ} \mathrm{C}\right)$, meaning that the crosslinked TPU also presents a microphase separation. However, the slight increase in the soft microphase $T_{g}$ with respect 
to the original TPU seems to indicate that in that case a larger amount of HS is dissolved in the SS-rich matrix.

\section{Choice of $T^{*}$}

As explained in the literature, to investigate the thermodynamic behavior of TPUs, an isothermal study from the melt can be a very useful tool. For this purpose, to erase all memory of the previous thermal history, a thermal pretreatment must be chosen. The isothermal $T^{*}$ at which the TPU must be heated for a few minutes has to exceed the maximum temperature of the multiple endotherms observed [38,18 ], which is approximately $190^{\circ} \mathrm{C}$ in our case (Fig. 1). However, it is well known that the urethane linkage becomes reversible at temperatures greater than $170^{\circ} \mathrm{C}$, as mentioned earlier. This paradoxical situation, implying a possible degradation of the TPU if the disappearance of the thermal memory of the TPU is wished, has been pointed out by many authors $[16,18,19,21]$. Figure 4 illustrates the decrease in the molar mass as a function of $T^{*}$. This degradation phenomenon might be explained by some MDI evaporation or isocyanate side reactions, which result in stoichiometric changes in the TPU. Finally, $T^{*}=220^{\circ} \mathrm{C}$ for $t^{*}=3 \mathrm{~min}$ was chosen as a compromise to erase the TPU thermal history and to homogenize the polymer.

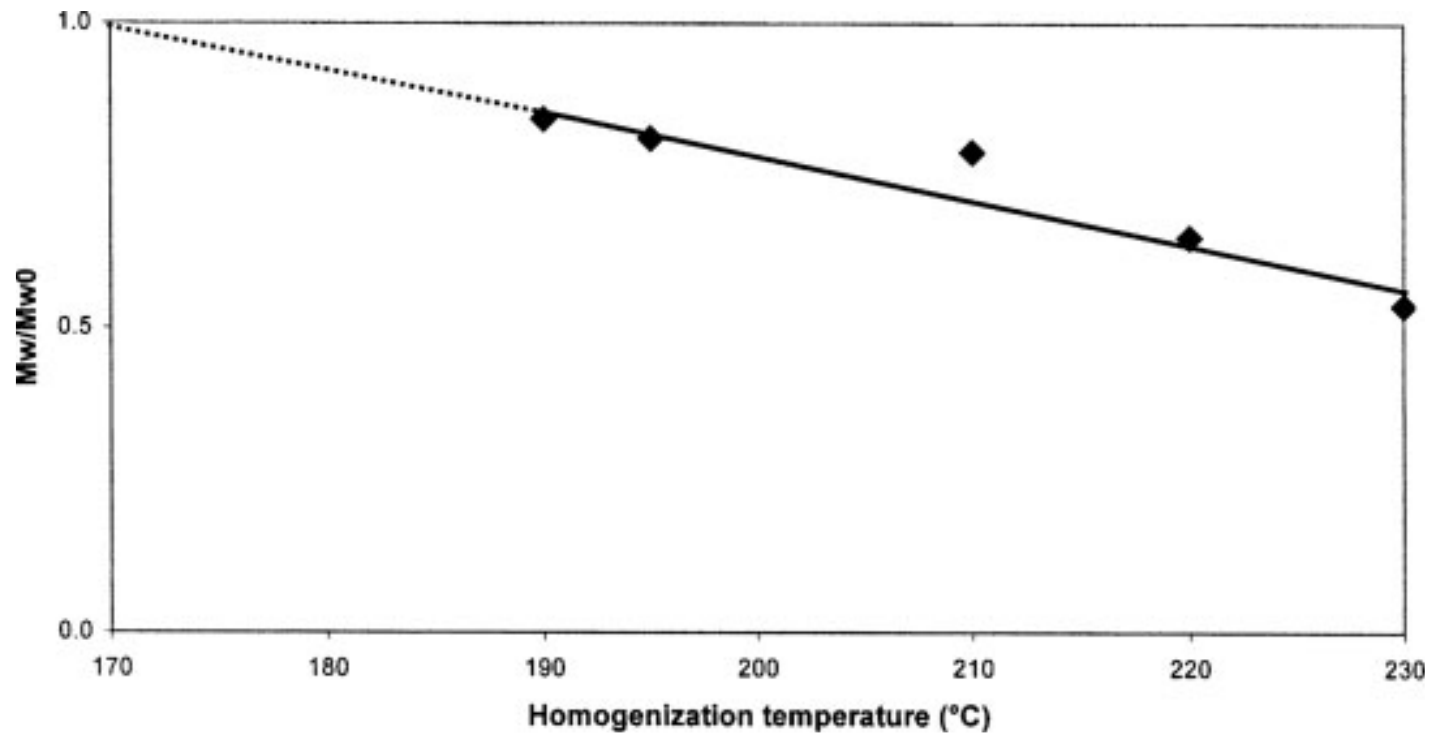

Figure 4. $M_{w} / M_{w 0}$ ratio as a function of $T^{*} . M_{w}$ is the molar mass of TPUs held at $T^{*}$ for time $t^{*}$, and $M_{w 0}$ is the molar mass of the initial TPU. The thermal treatment was as follows: $T^{*}=190-230^{\circ} \mathrm{C}, t^{*}=3$ $\min ,-q=50^{\circ} \mathrm{C} / \mathrm{min}$, and $t_{a}=0 \mathrm{~min}$.

The same treatment was then applied to the MDI-modified TPU wholly crosslinked at room temperature. The chemical gel was partially destroyed by the high-temperature step (Table II). The urethane and allophanate bonds forming the crosslinks became reversible at high temperatures $\left(>170^{\circ} \mathrm{C}\right)$, so the chemical gel was no longer permanent during the homogenization step and was not entirely reformed immediately after being rapidly cooled back to $T_{a}$. The advantage is that in this way, the gel fractions of the modified TPU can be controlled for the next studies (see the section "Influence of the Gel Content on TPU Microstructuration"). For example, when a thermal treatment identical to that of the initial TPU, $T^{*}=220^{\circ} \mathrm{C}$ and $t^{*}=3 \mathrm{~min}$, was applied to the crosslinked TPU, a new partially crosslinked polymer with $15 \%$ gel content was finally analyzed during the annealing from the melt. 
TABLE II. Evolution of the Gel Fraction as a Function of $T^{*}$ for the MDI-Modified TPU Initially Wholly Crosslinked at Room Temperature Under Ambient Conditions

\begin{tabular}{|c|c|}
\hline$T^{*}\left({ }^{\circ} \mathbf{C}\right)$ & Gel fraction (\%) \\
\hline 190 & 50 \\
200 & 30 \\
220 & 15 \\
\hline
\end{tabular}

The thermal treatment was as follows: $T^{*}=190-220^{\circ} \mathrm{C}, t^{*}=3 \mathrm{~min},-q=50^{\circ} \mathrm{C} / \mathrm{min}$, and $t_{a}=0 \mathrm{~min}$.

\section{Annealing from the melt}

After the homogenization step $\left(3 \mathrm{~min}\right.$ at $220^{\circ} \mathrm{C}$ ), the samples were quenched to $T_{a}=50-130^{\circ} \mathrm{C}$ and kept at $T_{a}$ for different $t_{a}{ }^{\prime}$ s. The DSC isothermal traces of the initial TPU (Fig. 5 ) clearly indicate an exothermic peak when $T_{a}$ exceeds $80^{\circ} \mathrm{C}$. This exotherm starts right at the beginning of the annealing and looks quite symmetrical above $T_{a}=100^{\circ} \mathrm{C}$; for example, for this particular $T_{a}$, the peak maximum is observed at $t_{a}=0.7 \mathrm{~min}$, and the phenomenon ends after about $2.5 \mathrm{~min}$; the corresponding enthalpy is $\Delta H_{100}=13.45 \mathrm{~J} / \mathrm{g}$. For $T_{a}<80^{\circ} \mathrm{C}$, the transformation is too fast and is pointed out by an exothermic peak during the quench, whatever the chosen quenching rate is. As $T_{a}$ increases, the rate of the phase transformation after the quench decreases strongly: the exotherm takes more than $1 \mathrm{~h}$ for high $T_{a}$ values $\left(T_{a}>120^{\circ} \mathrm{C}\right)$. This kind of behavior has already been observed for other PUs and can be associated with microphase separation, HS crystallization, or both phenomena [3-8].

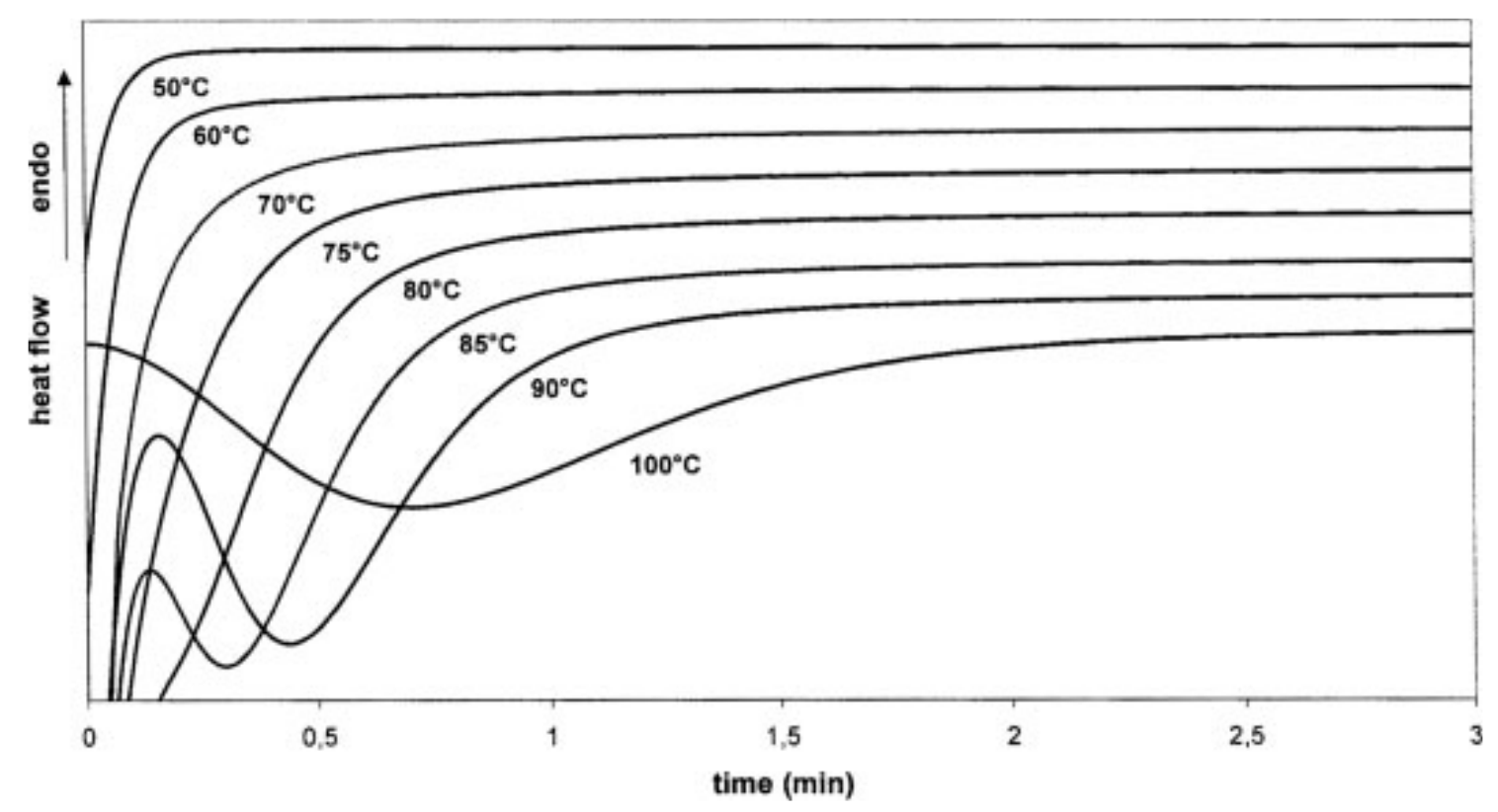

Figure 5. DSC isothermal traces of the TPUs during annealing at different $T_{a}$ 's. The thermal treatment was as follows: $T^{*}=220^{\circ} \mathrm{C}, t^{*}=3 \mathrm{~min},-q=50^{\circ} \mathrm{C} / \mathrm{min}, T_{a}=50-100^{\circ} \mathrm{C}$, and $t_{a}=15 \mathrm{~min}$. Only the first 3 min are represented here.

The DSC data were then plotted according to the Avrami equation: 


$$
\frac{\Delta H_{\max }-\Delta H_{t}}{\Delta H_{\max }}=\exp \left(-K t^{n}\right)
$$

where $\Delta H_{t}$ stands for the enthalpy at time $t, \Delta H_{\max }$ stands for the total enthalpy associated with the exotherm, and $K$ is the transformation rate constant. For an easier calculation, $\Delta H_{\max }$ was always considered equal to the total enthalpy, $\Delta H_{100}$, calculated for the initial TPU at the end of the annealing stage at $T_{a}=100^{\circ} \mathrm{C}$ (discussed previously). The calculated slope for the linear part of the curves ( $n$; not shown here) fluctuates between 3.3 and 3.8 according to $T_{a}$. These values differ from the literature results, especially from those of Lee and coworkers $[12,13](n=2)$, who used to associate the transition with an MST, and also from those of Nichetti and Grizutti [14] $(n=3)$, who attributed the exotherm to HS crystallization.

From our point of view, an Avrami plot cannot be a useful tool to distinguish MST from crystallization. As our aim was not to try to settle this question but to use the thermal behavior as a tool, we assume that the exothermic peak should be associated with a simultaneous process, that is, that both transformations occur. In the same way, a so-called degree of transformation can be evaluated from the $\Delta H_{t} / \Delta H_{\max }$ ratio (discussed previously) and plotted versus $t_{a}$. Figure 6 shows the results obtained for $T_{a}$ 's ranging from 100 to $120^{\circ} \mathrm{C}$. The curves display a sigmoidal shape, and complete transformation is always achieved but for higher and higher values of $t_{a}$ as $T_{a}$ increases.

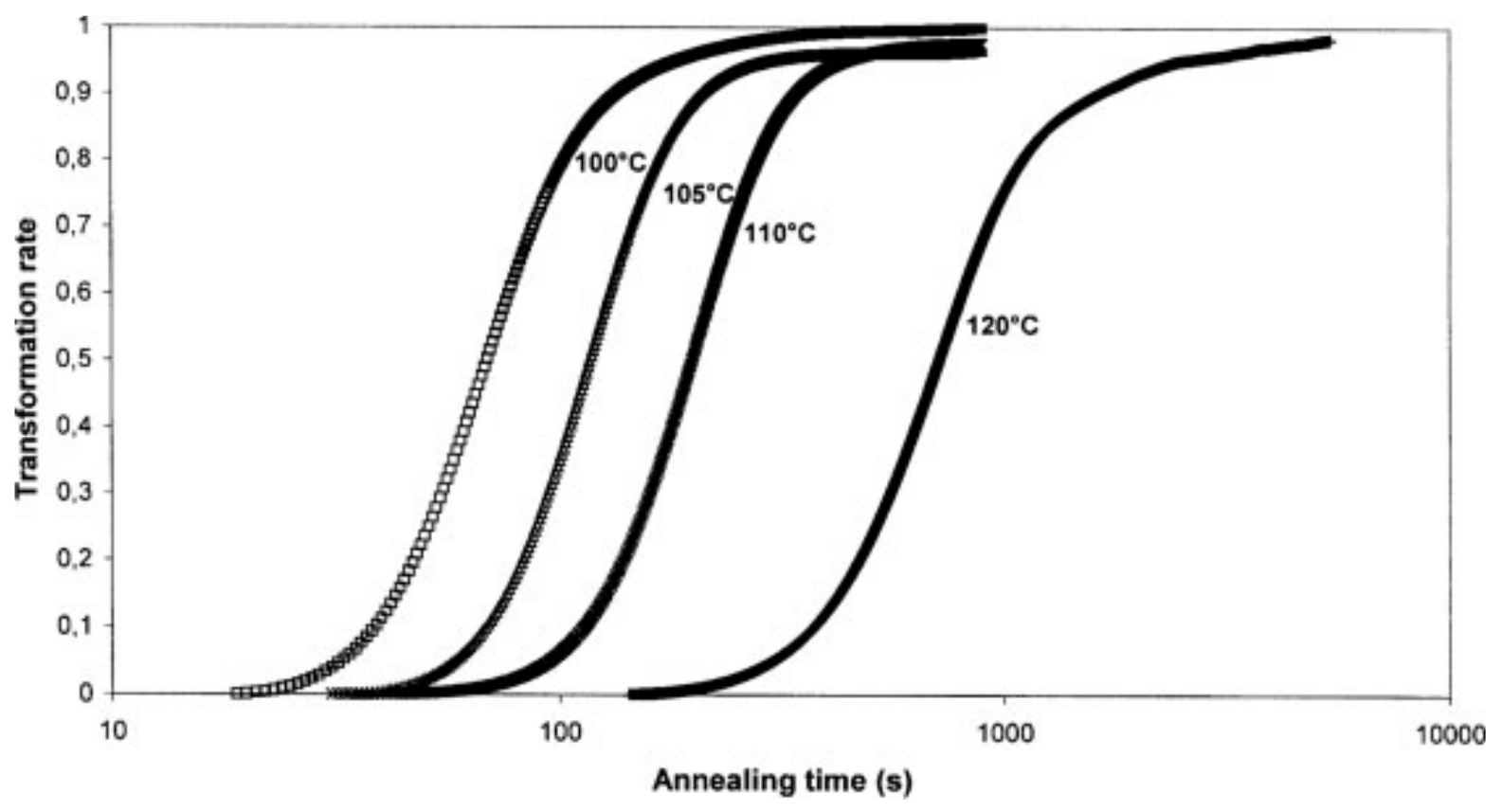

Figure 6. Transformation rate $\left(\Delta H_{t} / \Delta H_{\max }\right)$ for the initial TPU as a function of $t_{a}$ and $T_{a}$. The thermal treatment was as follows: initial gel content $=100 \%, T^{*}=220^{\circ} \mathrm{C}, t^{*}=3 \mathrm{~min},-q=50^{\circ} \mathrm{C} / \mathrm{min}$, gel content during the annealing $=15 \%$, and $T_{a}=100-120^{\circ} \mathrm{C}$.

The same thermal treatment $\left(T^{*} / t^{*}\right.$, quenching, $\left.T_{a} / t_{a}\right)$ was applied to the MDI-crosslinked TPU. After it cooled, a large part of the gel was destroyed, so the material presented a $15 \mathrm{wt} \%$ gel content during the annealing step. This sample was called 15-gelled TPU. Exothermic peaks were also observed by DSC during the isotherm from the melt. The transformation degree calculated from the $\Delta H_{t} / \Delta H_{\text {max }}$ ratio is presented in Figure 7 for both the initial and 15-gelled TPUs at different $T_{a}$ values. These experiments demonstrate the possibility for a partially crosslinked TPU to microstructure during the first minutes 
after cooling back from the melt. However, in comparison with the initial TPU, the process appears to be slower and not so complete. This difference can be easily explained by the higher viscosity of the modified material.

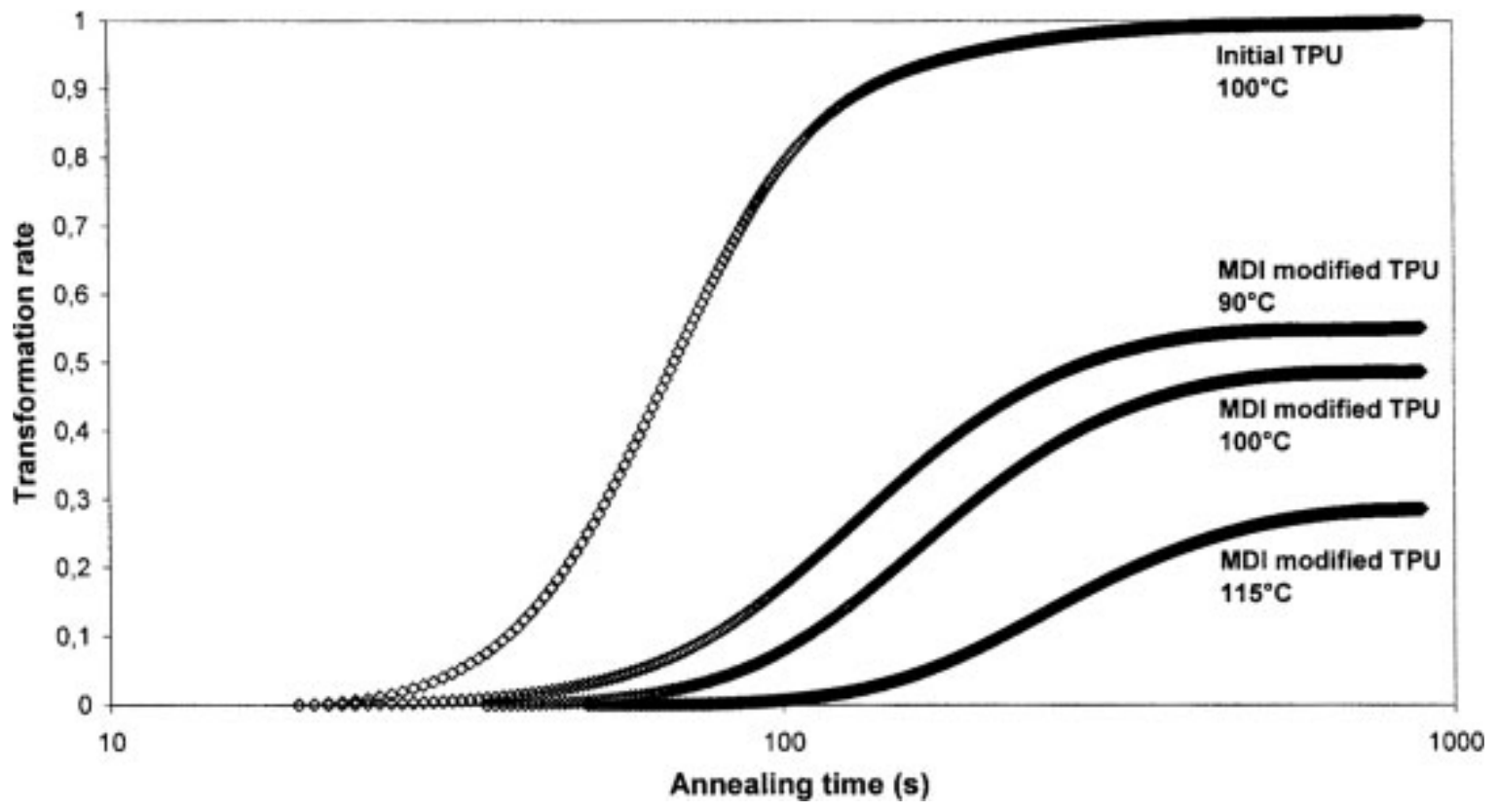

Figure 7. Transformation rate $\left(\Delta H_{t} / \Delta H_{\max }\right)$ for the initial TPU and the MDI-modified TPU as a function of $t_{a}$ for different $T_{a}$ 's. The thermal treatment was as follows: initial gel content $=100 \%, T^{*}=220^{\circ} \mathrm{C}$, $t^{*}=3 \mathrm{~min},-q=50^{\circ} \mathrm{C} / \mathrm{min}$, gel content during the annealing $=15 \%$, and $T_{a}=90-115^{\circ} \mathrm{C}$.

1. Grafted

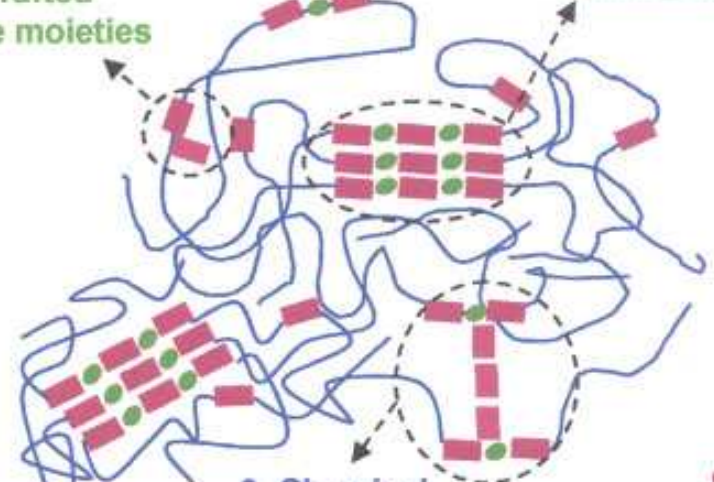

3. Chemical
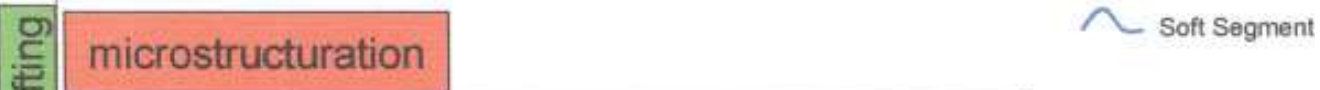

\section{NCO hydrolysis, $\mathrm{NH}_{2} / \mathrm{NCO}$ reactions}

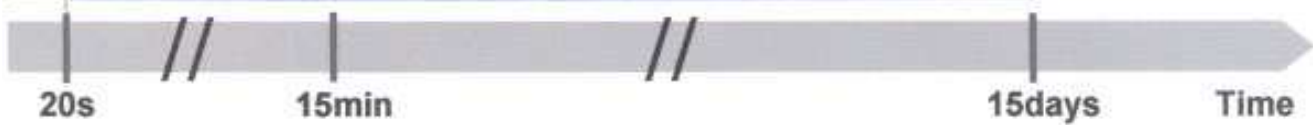

Figure 8. Schematic representation of the different elements present in the MDI-modified TPU microstructure and possible schedule of the successive events leading to their formation. 
If these transformations are possible in a partially crosslinked TPU, they must take place even more quickly in a TPU just grafted, that is, right after the chemical modification in the twin-screw extruder. To summarize, the different events taking place in the TPU during the modification can be schematized as shown in Figure 8:

- In the first step, some molecules are grafted onto the TPU chains during the process in the twinscrew extruder at a high temperature and during cooling.

- During or just after this step, a microstructuration process of the grafted TPU occurs, which consists more or less of simultaneous microphase separation and HS crystallization.

- At the same time, but at a slower rate, a crosslinking reaction by the hydrolysis of the isocyanate functions and urea bridge formation begins.

This ultimate step requires approximately 15 days under ambient conditions to obtain a wholly crosslinked TPU. This means that the chemical crosslinking process occurs in a microphase-separated TPU.

\section{Rheological behavior during annealing}

The same thermal treatment applied in DSC was also used in a rheometer apparatus to measure the modulus evolution during an isotherm from the melt. For the different $T_{a}$ values tested, Figure 9 is shown for the initial TPU. At the earlier stage of the annealing, $G^{\prime \prime}$ is higher than $G^{\prime}$. After the crossing of the storage and loss moduli, $G^{\prime}$ shows a strong increase. $A G^{\prime \prime}$ peak and a $\tan \delta$ convergence can be noticed at the same time.

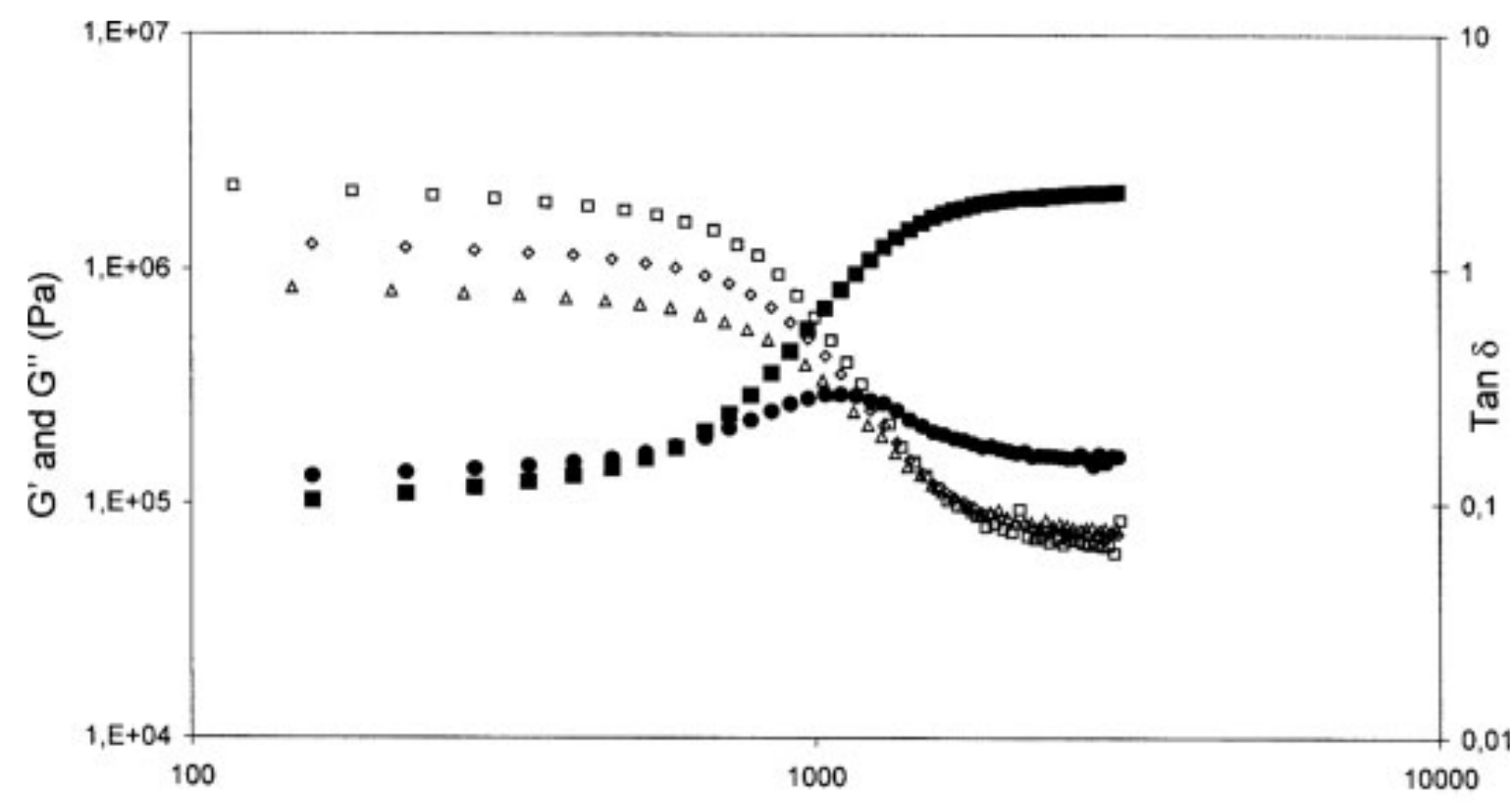

Annealing time (s)

Figure 9. ( $\square) G^{\prime}$ and $(\bullet) G^{\prime \prime}$ (at an oscillation frequency of $\omega=10 \mathrm{rad} / \mathrm{s}$ ) and $(\square, \diamond, \triangle) \tan \delta$ (at $\omega=1$, 10 and $46.4 \mathrm{rad} / \mathrm{s})$ as functions of $t_{a}$. The thermal treatment was as follows: $T^{*}=220^{\circ} \mathrm{C}, t^{*}=3 \mathrm{~min}$, $-q=50^{\circ} \mathrm{C} / \mathrm{min}$, and $T_{a}=120^{\circ} \mathrm{C}$. 
When these results are compared with the DSC results for the same $T_{a}$, it can be pointed out that the exothermic peak and modulus evolutions are occurring over the same period of time. As expected, the transformation (MST and HS crystallization) observed in DSC induces a macroscopic mechanical change. When $G^{\prime}$ and $G^{\prime \prime}$ are represented as a function of the oscillation frequency at different $t_{a}$ 's, a quite clear difference in the behavior is observed (Fig. 10). At the beginning, these two moduli are dependent on the frequency, whereas they become independent of the frequency at the end of the annealing process. This means that the TPU moves from a non-Newtonian behavior to a solid behavior during the isotherm. This sol-gel transition is correlated with microstructuration, the crystallized HS microdomains acting as physical crosslinks.

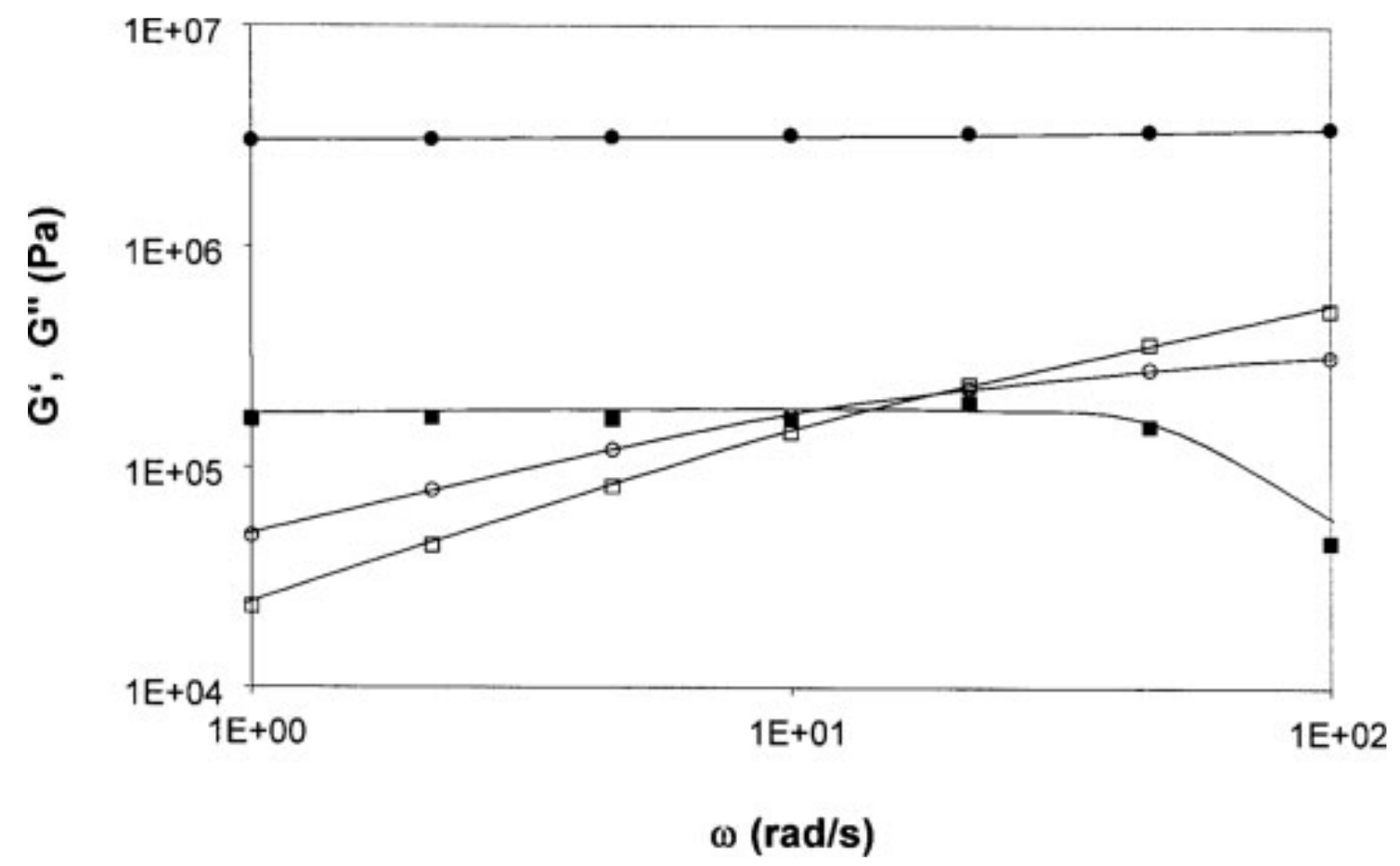

Figure 10. Plot of $(\Theta, \bigcirc) G^{\prime}$ and $(\square, \square) G^{\prime \prime}$ as functions of the oscillation frequency $(\omega)$ at the beginning and end of an annealing step $\left(T_{a}=110^{\circ} \mathrm{C}\right)$ for the pristine TPU $\left[\varepsilon=0.45\right.$; thermal treatment: $T^{*}=220^{\circ} \mathrm{C}$, $t^{*}=3 \mathrm{~min},-q=50^{\circ} \mathrm{C} / \mathrm{min}$, and $t_{a}=0(\bigcirc, \square)$ or $\left.166 \mathrm{~min}(\bullet, \square)\right]$.

During the 15-gelled TPU isotherm (Fig. 11), the formation of a physical gel cannot be observed. After the melting, the modified TPU still contains a gel fraction; consequently, the material presents a solid behavior during the entire annealing because of the chemical crosslinks, and quite logically for this material, $G^{\prime}$ is higher than that of the pristine homogenized TPU at the beginning of the annealing process. However, microstructuration, already observed in DSC, also results in a $G^{\prime}$ increase for 15gelled TPU. However, as pointed out in the DSC study, the transformation is much slower, and the storage modulus cannot reach the initial TPU values, even after a long $t_{a}$. 


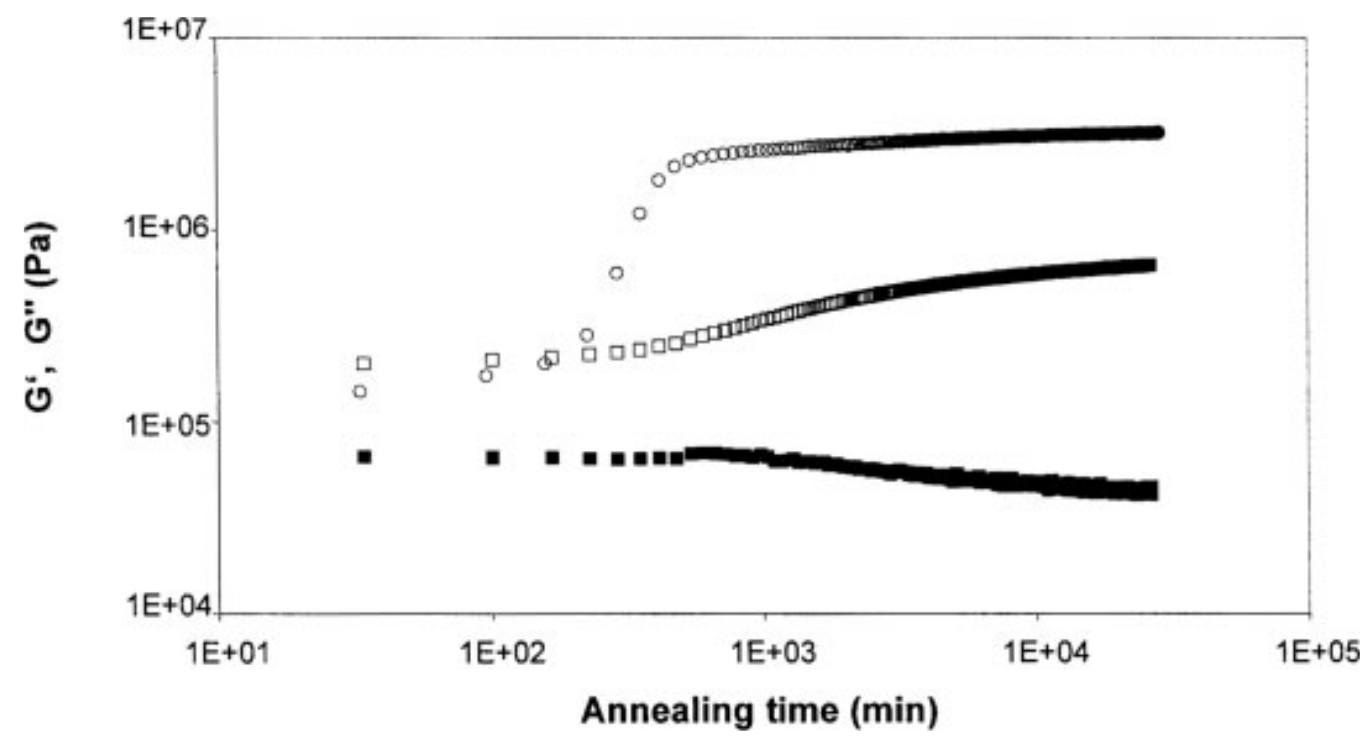

Figure 11. Evolution of $G^{\prime}$ and $G^{\prime \prime}$ during annealing $\left(T_{a}=110^{\circ} \mathrm{C}, T^{*}=220^{\circ} \mathrm{C}, t^{*}=3 \mathrm{~min},-q=50^{\circ} \mathrm{C} / \mathrm{min}\right.$, $\varepsilon=0.45$, and $\omega=10 \mathrm{rad} / \mathrm{s}):(\bigcirc) G^{\prime}$ for the initial TPU, $(\square) G^{\prime}$ for the 15-gelled TPU, and ( $\square$ ) $G^{\prime \prime}$ for the 15-gelled TPU.

\section{Heating scan after the annealing}

To learn more about the microstructure that formed during the annealing, the samples were finally heated. After the same thermal treatment $\left(T^{*} / t^{*}\right.$, quenching, and $\left.T_{a} / t_{a}=15 \mathrm{~min}\right)$, the samples were analyzed during a heating scan at $+q=10^{\circ} \mathrm{C} / \mathrm{min}$. The thermograms obtained for the initial TPU during these scans are presented in Figure 12. The same behavior was observed for different heating rates (5 and $20^{\circ} \mathrm{C} / \mathrm{min}$ ). Three characteristic peaks are distinguished that have been widely studied. As indicated by Leung and Koberstein [4], the low-temperature endotherm $\left(T_{1}\right)$ can be found at temperatures $20^{\circ} \mathrm{C}$ above $T_{a}$. The endotherm at an intermediate temperature $\left(T_{I I}\right)$, named MMT, is attributed to the microphase mixing of the HS-rich and SS-rich microdomains. The third endotherm at a high temperature $\left(T_{I I I}\right)$ corresponds to the melting $\left(T_{m}\right)$ of the microcrystalline $\mathrm{HS}$.

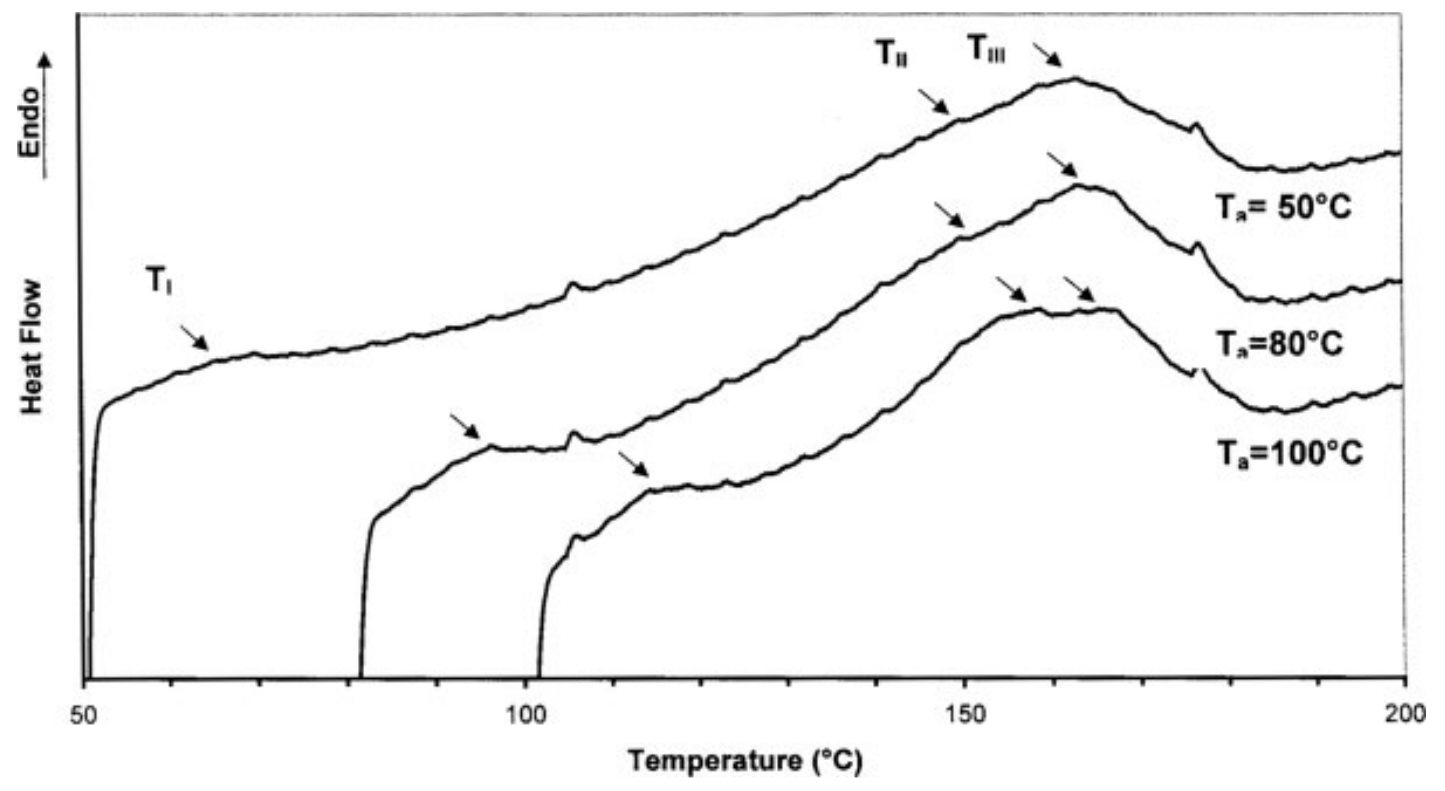

Figure 12. DSC thermograms obtained for unmodified TPU samples. The thermal treatment was as follows: $T^{*}=220^{\circ} \mathrm{C}, t^{*}=3 \mathrm{~min},-q=50^{\circ} \mathrm{C} / \mathrm{min}, T_{a}=50-100^{\circ} \mathrm{C}, t_{a}=15 \mathrm{~min}$, and $+q=10^{\circ} \mathrm{C} / \mathrm{min}$. 
This typical behavior is also observed for a 15-gelled TPU. Figure 13 presents the evolution of the peak temperatures [the microphase mixing transition temperature $\left(T_{\mathrm{MMT}}\right)$ and $T_{m}$ ] as a function of $T_{a}$ for both materials. In both cases, for initial and modified TPUs, a clear difference appears whether the TPUs have been annealed at temperatures below or above $80-100^{\circ} \mathrm{C}$. For $T_{a}<80^{\circ} \mathrm{C}$, the phase transformation was observed to be very fast and could even occur during the cooling back from $T^{*}$. The result of this fast phase transformation is the formation of HS microdomains with $T_{g}$ (HS) $\sim 80^{\circ} \mathrm{C}$. As the HS mobility is strongly reduced if $T_{a}<T_{g}(\mathrm{HS})$, crystallization may occur only during the heating step. Therefore, for $T_{a}<80^{\circ} \mathrm{C}$, both transitions occur at $T_{\mathrm{MMT}} \sim 150^{\circ} \mathrm{C}$ and $T_{m} \sim 163^{\circ} \mathrm{C}$ for the initial TPU.

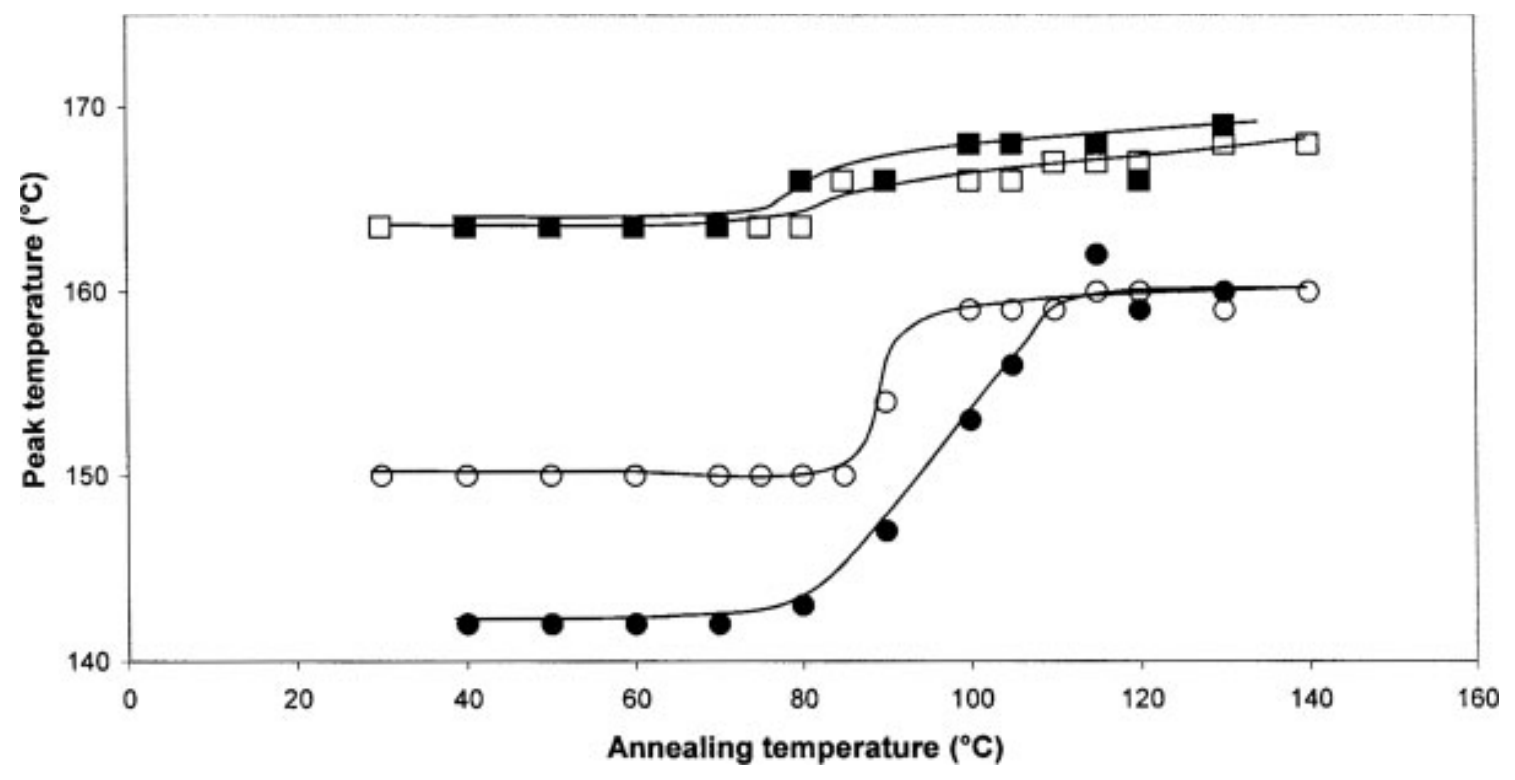

Figure 13. $(\bullet, \bigcirc) T_{\text {MMT }}$ and $(\square, \square) T_{m}$ as functions of $T_{a}$ for $(\bigcirc, \square)$ the initial TPU and $(\bullet, \square)$ the MDImodified TPU. The thermal treatment was as follows: $T^{*}=220^{\circ} \mathrm{C}, t^{*}=3 \mathrm{~min},-q=50^{\circ} \mathrm{C} / \mathrm{min}$, $T_{a}=50-100^{\circ} \mathrm{C}, t_{a}=15 \mathrm{~min}$, and $+q=10^{\circ} \mathrm{C} / \mathrm{min}$.

In the same $T_{a}$ range, $T_{\mathrm{MMT}}$ was measured at temperatures slightly lower $\left(T_{\mathrm{MMT}} \sim 142^{\circ} \mathrm{C}\right)$ for the $15-$ gelled TPU. During annealing, the viscosity of the medium did not allow a complete transformation, so the final purity of the microphases was inferior in the case of the modified TPU compared with the initial TPU. When the chosen $T_{a}$ 's are above $80-100^{\circ} \mathrm{C}$, HS crystallization becomes possible during the annealing isotherm. With increasing $T_{a}$, the development of the HS crystallinity is related to the increase in the segment mobility, and both $T_{\mathrm{MMT}}$ and $T_{m}$ increase, as indicated by some authors [4]. For the initial TPU, there is a gradual shift in the endothermic response from $T_{\mathrm{MMT}}=150^{\circ} \mathrm{C}$ to $T_{\mathrm{MMT}}=160^{\circ} \mathrm{C}$. In the same way, $T_{m}$ increases slightly with $T_{a}$ up to $167^{\circ} \mathrm{C}$. The same behavior can be noticed for the 15-gelled TPU.

\section{Influence of the gel content on TPU microstructuration}

To study the influence of the gel content on the MST/crystallization processes, different $T^{*}$ values were applied to the MDI-modified TPU. As the gel content of the material has been correlated with $T^{*}$ (see Table II), by the variation of this parameter, some partially crosslinked TPUs with different gel contents could be analyzed. Figure 14 presents the DSC thermograms of those materials during a heating scan after thermal treatments $\left(T^{*} / t^{*}\right.$, quenching, and $\left.T_{a} / t_{a}=15 \mathrm{~min}\right)$. The enthalpy of the endothermic peaks decreases with the gel content. As the MDI-modified TPU is a more viscous material than the 
initial TPU, one could expect that the homogenization step at too low temperatures would not be sufficient to erase the microstructuration. In that case, no exothermic peaks would be observed during the annealing. However, we also checked out previously that even a wholly crosslinked TPU (gel content $=100 \%$ ) exhibited large endotherms during a ramp in DSC. Therefore, if $T^{*}=190^{\circ} \mathrm{C}$ was not a sufficient temperature to disrupt the preexisting structure, endotherms should be present in the DSC thermograms during the post-annealing heating scan. This precaution taken, we can assume that microstructuration, that is, MST and crystallization, can hardly occur in a partially crosslinked TPU if the gel content of the sample exceeds $50 \%$, as pointed out by the preceding experiment. In this case, the viscosity of the medium is too high, and HSs are not mobile enough to segregate in HS-rich microdomains. As shown before, microstructuration results in the increase in the storage modulus. Therefore, such a chemically crosslinked but not microstructured TPU will not be interesting from a mechanical point of view; in other words, this experiment confirms that, as suggested in Figure 8 , it is essential for the optimal final properties to obtain the microstructuration of the grafted TPU before the formation of the chemical crosslinks.

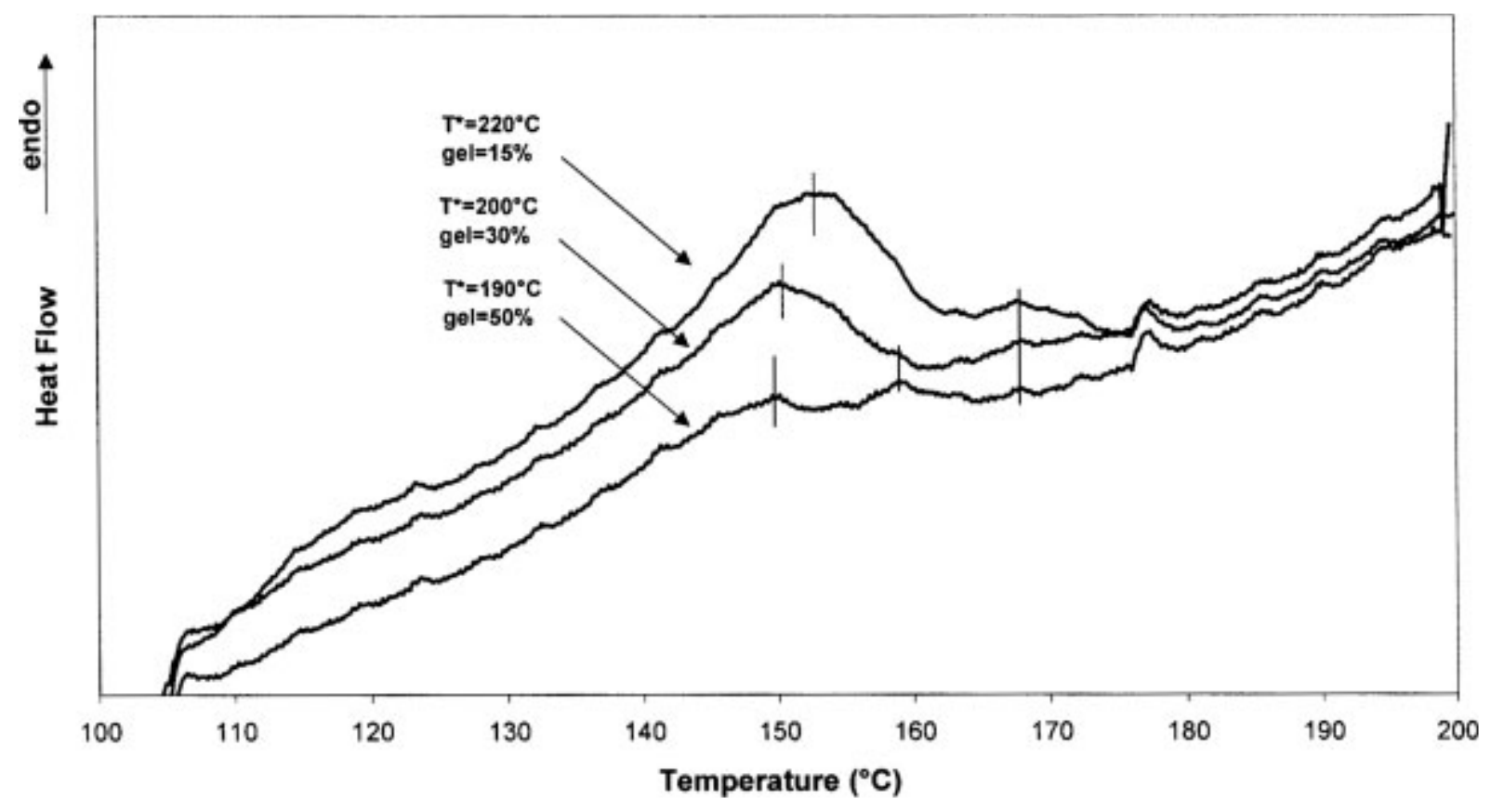

Figure 14. DSC thermograms obtained for MDI-modified TPU. The thermal treatment was as follows: $T^{*}=190-220^{\circ} \mathrm{C}, t^{*}=3 \mathrm{~min},-q=50^{\circ} \mathrm{C} / \mathrm{min}, T_{a}=100^{\circ} \mathrm{C}, t_{a}=15 \mathrm{~min}$, and $+q=10^{\circ} \mathrm{C} / \mathrm{min}$. The $T^{*}$ values and the resulting gel contents of the sample are indicated.

\section{Nonisothermal postannealing rheological study}

Microstructuration (microphase separation and HS crystallization) has been identified for the initial TPU and a partially crosslinked TPU (15-gelled TPU) during an isotherm from the melt. The result of the HS-rich and SS-rich microdomain segregation is the formation of a physical gel for the initial TPU, so the material presents a solid behavior once microstructuration has occurred. For the modified TPU, the solid behavior is provided by the chemical gel, all along the isotherm. Through the heating of these materials, the thermodynamic immiscibility between HSs and SSs decreases with the increase in the temperature until the disruption of the microphase-separated structure. An endothermic peak at temperatures around $142-160^{\circ} \mathrm{C}$ indicates the microphase mixing (MMT). This transition is followed by the melting of the $\mathrm{HS}$ microcrystallites at temperatures around $163-167^{\circ} \mathrm{C}$. 
Figure 15 presents the evolution of $\tan \delta$ as a function of temperature when the initial and modified TPUs are put through a weak deformation $\varepsilon(\varepsilon=0.45)$ at different oscillation frequencies. In both cases, a crossing of $\tan \delta$ is observed, which can be interpreted as a gel disruption. For the initial TPU, $\tan \delta$ crosses over a wide range of temperatures, that is, between 152 and $164^{\circ} \mathrm{C}$. This phenomenon is attributed to the disappearance of the physical gel. The correlation with the DSC characterization (Fig. 12) indicates that the physical gel, based on the HS-rich microdomains, is destroyed during the microphase mixing and HS melting transitions.

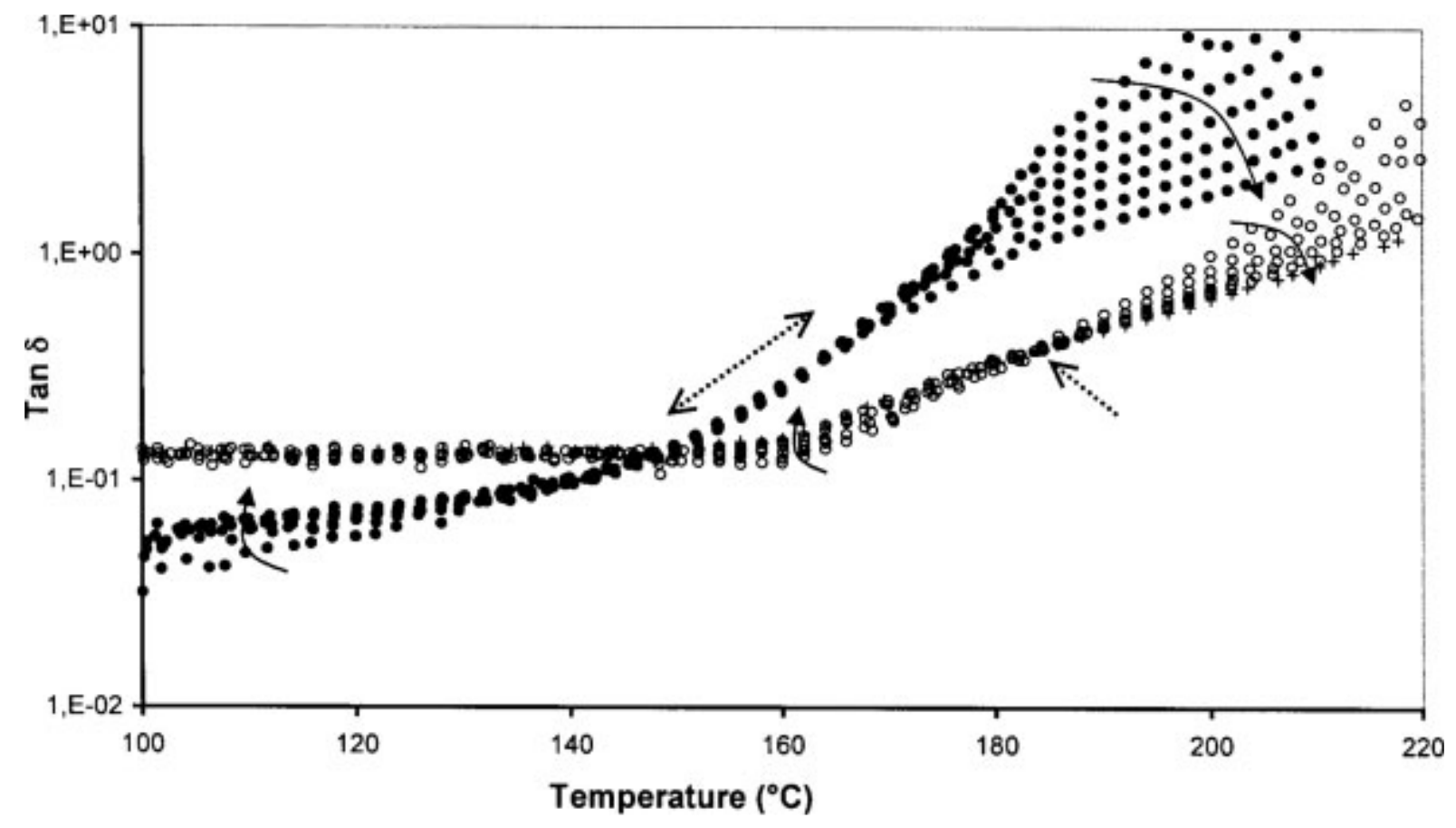

Figure 15. Tan $\delta$ as a function of the temperature for the initial TPU and the MDI-modified TPU. The thermal treatment was as follows: $T^{*}=220^{\circ} \mathrm{C}, t^{*}=3 \mathrm{~min},-q=50^{\circ} \mathrm{C} / \mathrm{min}, T_{a}=80^{\circ} \mathrm{C}, t_{a}=15 \mathrm{~min}$, and $+q=0.5^{\circ} \mathrm{C} / \mathrm{min}$. The gel content of the modified TPU was $15 \%$ during the annealing. The measurements were recorded at different oscillation frequencies between 1 and $100 \mathrm{rad} / \mathrm{s}$. The bent arrows indicate that the oscillation frequency increases. The dotted arrows indicate the $\tan \delta$ crossings. The filled symbols correspond to the initial TPU, and the open symbols correspond to the MDI-modified TPU.

For the MDI-modified TPU, these transitions, occurring in a quite similar interval of temperatures (143$166^{\circ} \mathrm{C}$ ), do not result in a $\tan \delta$ crossing. During the isothermal rheological study from the melt, we showed that the solid behavior of the modified TPU was due not to a physical gel but to a chemical gel. That is why the tan $\delta$ crossing at a higher temperature, $184^{\circ} \mathrm{C}$, is attributed to the disappearance of the chemical crosslinking. In fact, at temperatures above $T_{m}$, because of the reversibility of the urethane, allophanate, and urea linkages, this chemical gel is not a permanent gel but a reversible gel.

\section{Thermomechanical property improvement}

To draw conclusions on the thermomechanical properties, the evolution of $G^{\prime}$ as a function of the temperature was measured for the initial TPU, MDI-modified TPU, and tIPDI-modified TPU (Fig. 16) in an oscillatory mode with torsion jaws $\left(\varepsilon=0.45, \omega=6.28 \mathrm{rad} / \mathrm{s}\right.$, and $\left.+q=0.5^{\circ} \mathrm{C} / \mathrm{min}\right)$. The modified TPUs were wholly crosslinked at room temperature under ambient air conditions, and no additional thermal treatment was applied to the samples. At a low temperature $\left(<0^{\circ} \mathrm{C}\right)$, a strong decrease in $G^{\prime}$ is observed 
for all materials. This decrease is associated with the glass transition of the SS-rich microdomains, which occurs at a slightly higher temperature for the crosslinked TPU. Indeed, the microstructuration, microphase separation, and HS crystallization cannot be so complete for these materials, resulting in less pure microdomains and so in a higher $T_{g}$. Between 20 and $100^{\circ} \mathrm{C}, G^{\prime}$ remains constant, and the values of the storage modulus for the crosslinked TPU are lower in comparison with those of the initial TPU. This small difference is also due to the incomplete microphase separation of the crosslinked TPU.

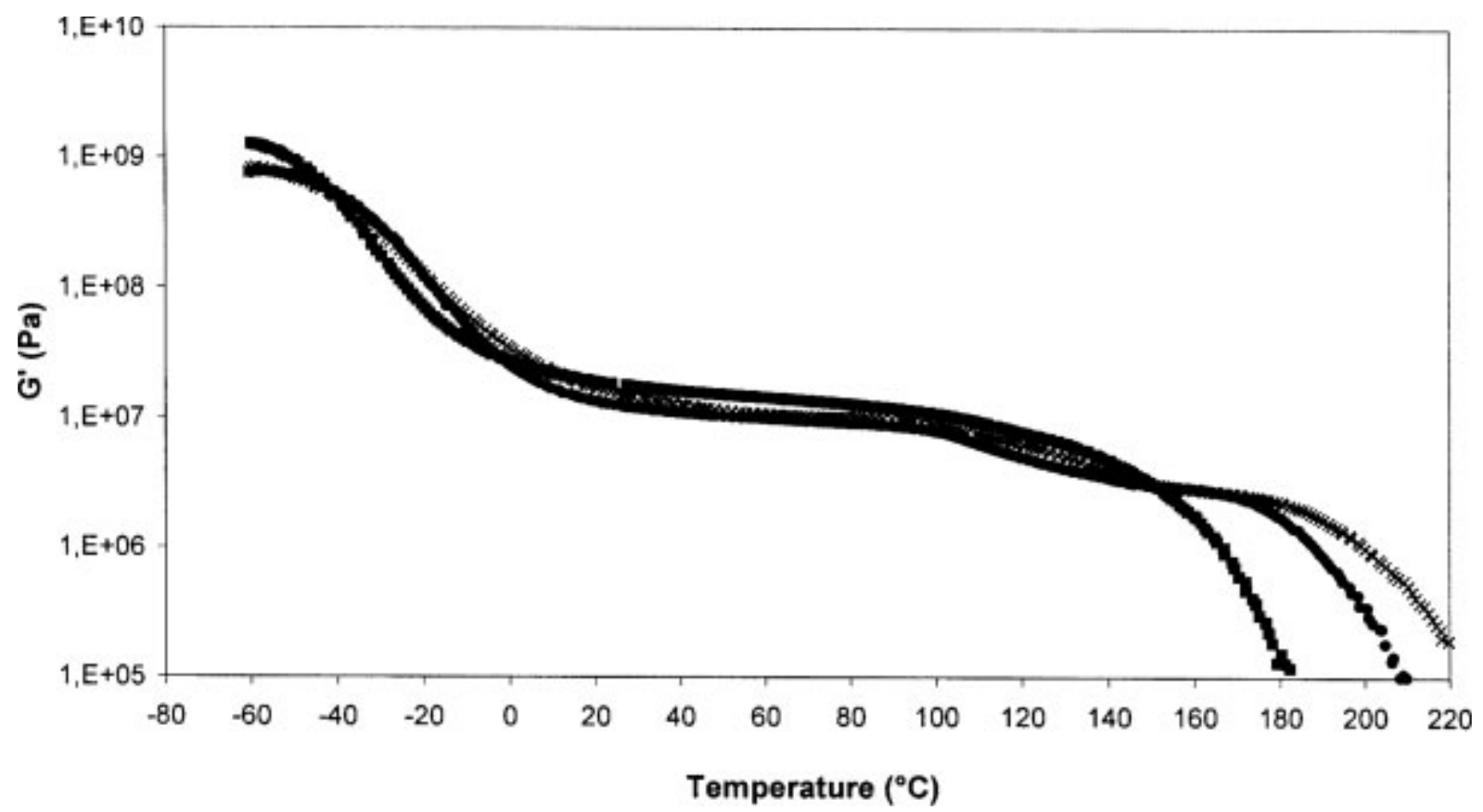

Figure 16. Evolution of $G^{\prime}$ as a function of the temperature: $(\mathbf{\square})$ the initial TPU, $(\mathbf{O})$ the MDI-modified TPU (isocyanate/urethane ratio $(\mathrm{i} / \mathrm{u})=0.107$ ), and $(X)$ the tIPDI-modified TPU (isocyanate/urethane ratio $(\mathrm{i} / \mathrm{u})=0.055)$.

The main differences between the modified and initial TPUs are observed at high temperatures $\left(>120^{\circ} \mathrm{C}\right)$. For the initial TPU, a strong decrease in $G^{\prime}$ is observed around $150^{\circ} \mathrm{C}$, which corresponds to the disruption of the microstructural organization, as shown by the $\tan \delta$ evolution with the temperature. For the crosslinked TPU, the microphase mixing and the HS melting have no impact on the mechanical properties of the material. The $G^{\prime}$ decrease, observed at a higher temperature, is due to the disappearance of the chemical crosslinking, as shown by the tan $\delta$ crossing at $184^{\circ} \mathrm{C}$ for the MDImodified TPU. The consequences of this difference are very important because the service temperature is increased by $30-40^{\circ} \mathrm{C}$ on account of the chemical crosslinks of the modified TPUs. For the tIPDI-modified TPU, the $G^{\prime}$ decrease occurs at a temperature $\sim 5-10^{\circ} \mathrm{C}$ higher, perhaps because of the higher functionality of the crosslinker or the higher stability of the chemical links formed by an aliphatic isocyanate.

\section{CONCLUSIONS}

In this study, a new strategy for grafting reactive moieties onto TPU chains, able to react and lead to crosslinked TPUs, has been developed. With this aim, a commercial TPU has been modified by polyisocyanates with reactive extrusion. The modified material obtained, if unevolved, can be further processed. After that, it can self-crosslink with ambient moisture. The modified and crosslinked TPU 
shows better mechanical behavior (creep) at middle temperatures of $80-100^{\circ} \mathrm{C}$ (the characterizations are not mentioned here) and better thermomechanical properties at high temperatures. Further analysis of these modified TPUs have made possible the identification of the reaction mechanisms leading to crosslinking. First of all, an analysis method was developed after a study on a model diurethane [33]. Then, allophanate functions were identified as the main reaction products between urethanes and polyisocyanates at high temperatures in bulk. This conclusion holds for both the urethanes of the commercial TPU and those of the model diurethane. We have found that ambient moisture is the unique condition necessary for the formation of urea bridges between the polymer chains. These bridges are formed by the hydrolysis and condensation of lateral isocyanate functions. DSC and rheological measurements have been used to characterize the structural transformations, microphase separation, and crystallization of the TPU and the modified TPU. The competition between the chemical reactions and physical microorganization has been studied. It has been demonstrated that the structural transformation rate is higher than the crosslinking rate for a partially crosslinked TPU. However, microphase separation is no longer possible for a TPU with a gel fraction higher than $50 \%$. For the initial TPU, we have pointed out the strong increase in $G^{\prime}$ during microstructuration and the further formation of a physical gel due to HS-rich microdomains acting as physical crosslinks. The microstructuration of the modified TPU also results in a $G^{\prime}$ increase, so the good mechanical properties of the initial TPU are preserved in a microstructured and crosslinked TPU. The chemical crosslinks of the modified TPU are reversible but allow an important increase in the thermomechanical properties at a high temperature.

The authors acknowledge financial support from Noveon and Nexans, together with fruitful advice and discussions with D. Lagneaux (Noveon) and J. Fournier and O. Pinto (Nexans). The authors are also grateful to F. Boisson (Service RMN de la Fédération de Recherche des Polyméristes Lyonnais, Vernaison, France) for ${ }^{1} \mathrm{H}-\mathrm{NMR}$ and ${ }^{13} \mathrm{C}-\mathrm{NMR}$ analysis.

\section{REFERENCES}

1. Cooper, S. L.; Tobolsky, A. V. J Appl Polym Sci 1966, 10, 1837.

2. Oertel, G. Chemistry, Raw Materials, Applications, Properties; Polyurethanes Handbook; Hanser: Munich, 1994.

3. Leung, L. M.; Koberstein, J. T. J Polym Sci Polym Phys Ed 1985, 23, 1883.

4. Leung, L. M.; Koberstein, J. T. Macromolecules 1986, 19, 706.

5. Koberstein, J. T.; Russell, T. P. Macromolecules 1986, 19, 714.

6. Koberstein, J. T.; Gancarz, I.; Clarke, T. C. J Polym Sci Part B: Polym Phys 1986, 24, 2487.

7. Galambos, A. F.; Russel, T. P.; Koberstein, J. J. Proceedings of the 18th Natas Conference, San Diego, CA, Sept 24-27, 1989; Paper 35.

8. Ryan, A. J.; Willkomm, W. R.; Bergstrom, T. B.; Macosko, C. W.; Koberstein, J. T.; Yu, C. C.; Russell, T. P. Macromolecules 1991, 24, 2883.

9. Chen, T. K.; Shieh, T. S.; Chui, J. Y. Macromolecules 1998, 31, 1312. 
10. Li, Y.; Gao, T.; Chu, B. Macromolecules 1992, 25, 1737.

11. Chu, B.; Gao, T.; Li, Y.; Wang, J.; Desper, C. R.; Byrne, C. A. Macromolecules 1992, 25, 5724.

12. Lee, H. S.; Wang, Y. K.; MacKnight, W. J.; Hsu, S. L. Macromolecules 1988, 21, 270.

13. Lee, H. S.; Hsu, S. L. Macromolecules 1989, 22, 1100.

14. Nichetti, D.; Grizzuti, N. Polym Eng Sci 2004, 44, 1514.

15. Cossar, S.; Nichetti, D.; Grizzuti, N. J Rheol 2004, 48, 691.

16. Yang, W. P.; Macosko, C. W.; Wellinghoff, S. T. Polymer 1986, 27, 1235.

17. Camberlin, Y.; Pascault, J. P.; Letoffe, J. M.; Claudy, P. J Polym Sci Polym Chem Ed 1982, 20, 383.

18. Saiani, A.; Daunch, W. A.; Verbeke, H.; Leenslag, J.-W.; Higgins, J. S. Macromolecules 2001, 34, 9059.

19. Yoon, P. J.; Han, C. D. Macromolecules 2000, 33, 2171.

20. Shieh, Y. T.; Chen, H. T.; Liu, K. H.; Twu, Y. K. J Polym Sci Part A: Polym Chem 1999, 37, 4126.

21. Hentschel, T.; Münstedt, H. Polymer 2001, 42, 3195.

22. Hu, W.; Koberstein, J. T. J Polym Sci Part B: Polym Phys 1994, 32, 437.

23. Kothandaraman, H.; Venkatarao, K.; Chithambara Thanoo, B. J Appl Polym Sci 1990, 39, 943.

24. Petrovic, Z. S.; llavky, M.; Dusek, K.; Vidakovic, M.; Javni, I.; Banjanin, B. J Appl Polym Sci 1991, 42, 391.

25. Tsai, Y.-M.; Yu, T.-L.; Tseng, Y.-H. Polym Int 1998, 47, 445.

26. Dusek, K.; Spirkova, M.; Havlicek, I. Macromolecules 1990, 23, 1774.

27. Dimier, F.; Sbirrazzuoli, N.; Vergnes, B.; Vincent, M. Polym Eng Sci 2004, 44, 518.

28. Furukawa, M.; Shiiba, T.; Murata, S. Polymer 1999, 40, 1791.

29. Lagneaux, D.; Pascault, J. P.; Dumon, M.; Méchin, F. Fr. Pat. 0113849 (2003); PCT/Fr. Pat. 02/03646 (2003).

30. Bräuer, M.; Hupfer, B.; Nagel, J.; Lehmann, D. Polym Eng Sci 2002, 42, 859.

31. Dassin, S.; Dumon, M.; Méchin, F.; Pascault, J. P. Polym Eng Sci 2002, 42, 1724.

32. Dolmaire, N.; Méchin, F.; Espuche, E.; Pascault, J. P. J Polym Sci Part B: Polym Phys 2006, 44, 48.

33. Lapprand, A.; Boisson, F.; Delolme, F.; Méchin, F.; Pascault, J.-P. Polym Degrad Stab 2005, 90, 363.

34. Burel, F.; Feldman, A.; Loutelier-Bourhis, C.; Bunel, C. e-Polymers 2004, 011, 1. 